
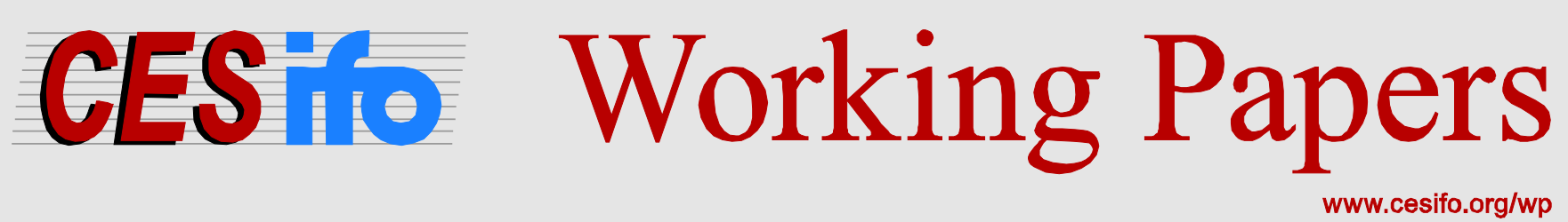

\title{
Three Family Policies to Reconcile Fertility and Labor Supply
}

\author{
Robert Fenge \\ Lisa Stadler
}

CESIFO WORKING PAPER NO. 4922

CATEgORY 1: Public FinANCE

JULY 2014

An electronic version of the paper may be downloaded

- from the SSRN website:

- from the RePEc website:

- from the CESifo website:

wWw.SSRN.com

www.RePEc.org

www.CESifo-group.org/wp

\section{CESifo}




\title{
Three Family Policies to Reconcile Fertility and Labor Supply
}

\begin{abstract}
In a model with endogenous fertility and labor supply three instruments of family policies are analyzed: child benefits, subsidies for external child care, and parental leave payments. We compare the impact on the quantity and quality of children, the secondary earner's labor supply and welfare. Child benefits and subsidies for external child care are more effective in balancing family and work than parental leave payments. The welfare analysis shows that the introduction of subsidies for external child care into a welfare program with child benefits makes families better off.
\end{abstract}

JEL-Code: H310, H530, J130, J220.

Keywords: fertility, quality of children, child care, secondary earner's labor supply, time allocation, parental leave payments.

\author{
Robert Fenge* \\ University of Rostock \\ Department of Economics \\ Ulmenstraße 69 \\ Germany - 18057 Rostock \\ robert.fenge@uni-rostock.de
}

\author{
Lisa Stadler \\ University of Munich \\ Department of Economics \\ Ludwigstraße 28 \\ Germany - 80539 Munich \\ Lisa.Stadler@econ.Imu.de
}

*corresponding author

July 22, 2014 


\section{Introduction}

There has been a steady and significant decline in birth rates in most industrialized countries over the last 40 years. According to OECD statistics, total fertility rates in the 1970s were well above 2 children per woman and are now as low as 1.4 in countries like Italy, Spain, Germany, and Japan. Within the high-income countries of the world, today no country is solidly above the fertility rate of 2.1 children per woman that is needed to replace the population at a constant level. Some other countries like France, Sweden, and the United Kingdom managed to counteract the downside trend and to re-increase the birth rates. Important factors linked to the decline of birth rates are higher incomes, and hence higher opportunity costs of children, the rise in labor-force participation of women, and the expansion of social security systems in developed countries. According to Becker (1960 and 1981) and Becker and Lewis (1973), income increases may reduce fertility if the income elasticity for the quality of children exceeds the income elasticity for the quantity of children. Willis (1973) points out that increasing female wages will increase female labor-force participation and thus have a negative impact on the demand for children because of the higher opportunity costs. Sinn (2005) emphasizes the redundancy of having children as providers for old-age in the presence of social security systems and the positive externality of children in pay-as-you-go pension systems.

Due to the aging process associated with this decline in fertility, the developed countries are facing severe challenges for social security systems and labor markets. In the last decade, many developed countries have implemented political incentives to correct for the low fertility rates and to improve the income positions of families. A central role in those family programs plays the compatibility of working and having children. High opportunity costs of children arise because a parent has to reduce labor supply in order to take care of the children. The foregone wage income and also the lost time of on-the-job training and qualification which reduces the wage opportunities in the future is a strong obstacle to raising children. Family policies are designed to provide relief to this quandary and to give secondary earners the opportunity to take up employment and at the same time to bring up children.

However, increasing fertility may not be a goal of public policies per se. A higher number of children comes at a cost in terms of consumption and income of the parents. Even for children the quality of life may decrease if policies address only the quantity of children. Therefore a comparative static analysis of policy instruments with respect to fertility and labor supply is not sufficient to assess the effects. For a comparison of family policies a welfare analysis is 
necessary which takes account of all impacts on the families, who in particular carry the costs of financing the family policies as tax payers.

This paper presents a comparison of benefit programs for families and analyzes the effects on welfare, fertility, employment and investments in quality of children within a model with endogenous fertility and labor supply of a secondary earner. In our model we do not present another justification for family policies. Nor do we analyze reasons why the government should foster the number of children in the economy. This has been discussed in several other studies (see e.g. Cigno, 1991, Apps and Rees, 2004). Instead we are concerned with the relative performance of instruments of family policies which are widely used in developed countries. We analyze how effectively instruments of family policies can achieve a compatibility of family and work. Furthermore, a welfare analysis compares the effects of public policies on the well-being of families. We use a standard Beckerian welfare approach to families and consider the number of children and a quality function of children which both enters the parental utility. In such a framework we analyze the effects of child benefits, a child subsidy on bought-in child care and parental leave payments.

Child benefits have been implemented in almost all OECD countries and there have been several empirical studies (e.g. Gauthier and Hatzius, 1997, Cigno et al, 2003, Laroque and Salanié, 2005) showing that they have a positive impact on the demand for children. Nevertheless countries such as Germany with very low fertility rates and relatively low female employment rates pay relatively high child benefits. Policy differences between high and low fertility countries as well as countries with high and low female employment rates can rather be found in the rates for parental leave payments, child care subsidies, and tax breaks towards families.

Both Sweden and France have achieved to keep their fertility rates relatively high and both countries have well developed subsidized care systems. This might lead to the conclusion that investing in child care is an important political instrument to help increasing fertility rates. In the empirical literature one finds mixed evidence about the success of child care subsidies in fostering fertility. While Hank et al (2004) find positive effects of full-time subsidized child care on fertility for Germany, Haan and Wrohlich (2009) only find significant effects for highly-educated women and women who give birth for the first time.

The third policy parameter we want to analyze, the rate of parental leave payments, has especially been implemented in Germany and Sweden. In the empirical literature one also finds mixed evidence on the effects of parental leave payments on fertility and the secondary earner's labor supply. Spiess and Wrohlich (2008) simulate fiscal costs and expected labor 
market outcomes of a parental leave benefit reform in Germany. They provide evidence that all income groups benefit and that in the second year, mothers increase working hours and labor market participation significantly. Lalive and Zweimüller (2009) show that an extension of the Austrian parental leave period increases fertility but lengthens the time women spend at home. Other studies also show that leave expansions are associated with increased leavetaking (e.g. Pronzato, 2009, Han et al., 2009). Bergemann and Riphahn (2011) study the labor supply effects of a major change in the maternity leave benefit system in Germany on the intention of mothers to return to the labor market. They find that the change to a benefit system that replaced two-thirds of pre-birth earnings for at most one year succeeded in speeding up mothers' return to work.

In this paper, we complement the empirical literature by analyzing a simple model of household decisions on children and labor supply and isolating the incentive effects of the policy instruments which sometimes work in opposite directions. The results explain some of the ambiguity of the empirical evidence. There is also some theoretical literature on family decisions and family policies (see e.g. Cigno 1986; Ermisch 1989; Apps and Rees 2004; Cigno and Luporini 2011). This paper contributes to this literature by analyzing the differential effects of the chosen policy instruments on fertility and labor supply and addressing the problem of work-family balance. The differential effects of a budget-neutral policy change, in particular, are important to compare the relative performance of the policy instruments in fostering the number of children or parental labor supply. We qualify our results by redistributional effects and distinguish between high- and low-income earners. Furthermore, we add a welfare analysis or - to be accurate - an analysis of the policy effects on the parental utility which comprises the number and quality (of life) of children. This enables us to calculate the distortions of the different policies and to compare them regarding to the benefit of parents.

Our main results are the following. Comparing child benefits with subsidies for external child care we find that a policy change with a higher subsidy for external child care and a budgetneutral reduction of child benefits induces negative incentives for fertility but increases the employment rate of a secondary earner in a family who is net contributor to the policy change. In contrast an exchange of child benefits and parental leave payments may improve the compatibility of family and work. If we consider identical families (or families with average income) a policy of increasing child benefits combined with a budget-neutral decrease of parental leave payments sets positive incentives for having children and the demand for external child care and, at the same time, increases the labor supply of the parents. For 
families with non-average wages this policy change stimulates fertility and external child care only for parents with low opportunity costs of staying at home with the children. However, the effect on labor supply of the secondary earner is ambiguous. Comparing the subsidy for external child care with parental leave payments a budget-neutral policy reform that increases the subsidy and reduces the leave payments has a positive effect on the secondary earner's employment and the demand for external child care in the case of identical families. Furthermore, fertility increases if the families respond less elastic to price changes of external child care than to the change of opportunity costs of parental child care. These results are based on the fact that parental leave payments have a negative impact on the employment of parents because they induce the same incentives as an implicit wage tax on continued work. Therefore, the other two policy instruments are more effective in fostering fertility while at the same time maintaining incentives for work.

The welfare analysis includes all the effects of the policy instruments on parental utility, in particular the consumption effects. Here we find that the introduction of subsidies for external child care up to a certain provision level and a budget-neutral reduction of child benefits make all families better off in the case of identical households. In the case of heterogeneous households it is welfare improving for all families who are net recipients of the subsidy system. The welfare of the families who are net payers can go in either direction depending on the tax burden they face relative to the advantage of receiving subsidies. Furthermore, introducing the subsidies and cutting the parental leave payments can increase parental utility in families who respond more elastic to opportunity costs than prices of external child care if the replacement rate of the leave payments for net wage income is very high.

In the next section we introduce the model. Section 3 presents the comparative static results. In section 4 , we calculate the welfare effects of exchanging family policies and section 5 concludes.

\section{The model}

For simplicity, we divide the life cycle of each person into two phases of the same duration. During the first phase, a person entirely depends on parental support, while in the second, the adult person allocates his or her time to either working and thus contributing to family income or to raising children. For ease of exposition, we also assume that all men and women are neatly paired off into conventional families. Family $i$ 's decisions are assumed to be taken by 
the parents who derive utility from their own consumption, $c_{i}$, their number of children, $n_{i}$, and their children's quality of life, $q_{i}$, according to the additively separable utility function

$$
U\left(c_{i}, n_{i}, q_{i}\right)=u\left(c_{i}\right)+u\left(n_{i}\right)+u\left(q_{i}\right)
$$

for $i \in\{1, \ldots, N\}$. We assume the utility function to be continuous, strictly concave, and strictly increasing in all arguments. The quality per child, $q_{i}$, can be understood as a good produced domestically by the parents who use as inputs time spent with the child and a childspecific consumption good, $z_{i}$, bought on the market. The price on the market for the childspecific consumption good is $B$. For simplicity, we assume that only the secondary earner of family $i$ spends time with the children. Time spent with a child can be divided into the secondary earner's own time, $h_{i}$, and the time the child spends at external child care, $g_{i}$. The market price for child care, $g_{i}$, is denoted by $\pi$. The strictly concave domestic production function for quality is given by

$$
q_{i}=q\left(h_{i}, g_{i}, z_{i}\right)
$$

and increases monotonically in all arguments.

The secondary earner allocates her time to working which yields wage at the rate $w_{i}$ and to leisure time. We assume that child rearing is the only domestic time requiring parental time so that she spends her leisure time completely with the children. Through the endogeneity of $n_{i}$, the secondary earner's labor supply is also endogenous. If she has $n_{i}$ children her parental time equals $h_{i} n_{i}$. The rest of secondary earner $i$ 's total time is working time and given by $L_{i}=1-h_{i} n_{i}$, her gross income therefore equals $w_{i} L_{i}$. Secondary earners carrying a larger wage rate $w_{i}$ thus have higher opportunity costs of raising children. The primary earner allocates all her time to working and her gross salary is $Y$.

The family’s budget constraint is given by

$$
(1-t)\left(Y+w_{i} L_{i}\right)+\alpha n_{i}+\gamma w_{i}(1-t) h_{i} n_{i}=c_{i}+B z_{i} n_{i}+(1-\beta) \pi g_{i} n_{i}
$$

where $\alpha$ represents the child benefit, $\beta$ the share of bought-in child care which is subsidized and $\gamma$ the share of foregone net wage income of the secondary earner staying at home with the children which is granted as parental leave payment by the government.

The parents choose consumption, $c_{i}$, the number of children, $n_{i}$, the secondary earner's time spent with a child, $h_{i}$, the amount of bought-in child care, $g_{i}$, and the child-specific consumption, $z_{i}$, so as to maximize their utility, $u\left(c_{i}, n_{i}, q_{i}\right)$, by taking account of the child's 
quality production and their budget constraint. We abbreviate the first derivative of a function $y(x)$ by $y_{x}$.

The household decision problem is given by

$$
\begin{aligned}
& \max _{c_{i}, n_{i}, h_{i}, g_{i}, z_{i}} u\left(c_{i}, n_{i}, q_{i}\left(h_{i}, g_{i}, z_{i}\right)\right) \\
& \text { s.t. }(1-t)\left(Y+w_{i} L_{i}\right)+\alpha n_{i}+\gamma w_{i}(1-t) h_{i} n_{i}=c_{i}+B z_{i} n_{i}+(1-\beta) \pi g_{i} n_{i}
\end{aligned}
$$

The first-order conditions yield the following necessary and sufficient conditions of the concave maximization problem:

$$
\begin{aligned}
& \frac{u_{n}}{u_{c}}=B z_{i}+(1-\beta) \pi g_{i}+w_{i}(1-t)(1-\gamma) h_{i}-\alpha \equiv P_{n, i} \\
& \frac{u_{q}}{u_{c}} q_{h}=w_{i}(1-t)(1-\gamma) n_{i} \equiv P_{q_{h}, i} \\
& \frac{u_{q}}{u_{c}} q_{g}=(1-\beta) \pi n_{i} \equiv P_{q_{g}, i} \\
& \frac{u_{q}}{u_{c}} q_{z}=B n_{i} \equiv P_{q_{z}, i}
\end{aligned}
$$

All conditions have the well-known meaning that the marginal rate of substitution between the respective decision variables has to be equal to the marginal rate of transformation at the utility maximum. A variation in any of the policy parameters may affect the price of quantity as well as quality of children. Next to costs of parental time, the upbringing of children also incurs a cost per child, $B z_{i}$, which covers child-specific consumption expenditure. The net cost of children $P_{n, i}$ in (5) is therefore composed of family $i$ 's consumption cost per child plus the net cost of external child care plus the opportunity cost of forgone net wage income of the secondary earner minus the child benefits. Children are considered consumption goods with positive net costs. The marginal net price of a child, $P_{n, i}$, decreases with a higher child benefit, $\alpha$, as well as with a higher subsidy for child care, $\beta$, and higher parental leave payments, $\gamma$.

The marginal net price of parental time spent with the children, $P_{q_{h, i}}$, in (6) consists of the net wage loss while the marginal price for external child care, $P_{q_{g}, i}$, in (7) equals the net cost for the utilization of this service. Obviously, child benefits have no effect on the price of quality while the subsidy for child care decreases the price for bought-in child care and the parental leave payment reduces the net price of parental time spent with the child. 
In the following, the net wage is abbreviated by $\widehat{w}_{i}=(1-t) w_{i}$ and the first derivative of utility with respect to the quality inputs $x_{i}=h_{i}, g_{i}, z_{i}, U_{q} q_{x}>0$, by $U_{q_{x}}$ and the second derivative, $U_{q} q_{x x}+U_{q q} q_{x} q_{x}<0$, by $U_{q_{x} q_{x}}$.

\section{Comparative Statics: The effects of changes in the family policy system}

First, we analyze the absolute effects of the policy instruments on fertility, secondary earner's labor supply, the demand for external child care and parental and child-specific consumption. Second, we compare the policies by investigating the differential or relative effects of exchanging mutually the instruments in a budget-neutral reform. By implicit differentiation of the first-order conditions (5)-(8) we derive the results and present in the following the impact on fertility, labor supply and demand for external child care. The derivation and the other effects on consumption can be found in Appendix A.

\subsection{Absolute effects}

We start by analyzing the effects of a variation in the child benefit rate on quantity and quality of children. The effect of an increase of the child benefit rate on the quantity of children

$$
\frac{\partial n_{i}}{\partial \alpha}=-s_{n n}-n_{i} i_{n}=\frac{1}{D_{i}} u_{q_{h} q_{h}} u_{q_{g} q_{g}} u_{q_{z} q_{z}}\left(u_{c}-n_{i} u_{c c} P_{n, i}\right)>0
$$

is positive as the determinant of the bordered Hessian matrix is negative $\left(D_{i}<0\right)$ and $\left(u_{c}-n_{i} u_{c c} P_{n, i}\right)>0$. As expected, additional child benefits encourage fertility as they reduce the cost of having children. The income effect, $-n i_{n}$, with respect to $\alpha$ is positive and the substitution effect, $-s_{n n}$, is positive since an increase in $\alpha$ decreases the marginal net price of a child in (5). The size of the effect is driven by family $i$ 's number of children, $n_{i}$, and their marginal price for a child, $P_{n, i}$. The impact of an increase of $\alpha$ is therefore larger for high income families. On the contrary, secondary earners with a smaller wage rate invest more in parental consumption when $\alpha$ is increased (see Appendix A).

An increase of the child benefit rate has also a positive effect on both parental time and time the child spends in external child care as $\left(n_{i} u_{c c} u_{n n}+2 u_{n} u_{c c}-\frac{u_{c}^{2}}{n_{i}}\right)>0$ (see Appendix A): 
$q_{h} \frac{\partial h_{i}}{\partial \alpha}=s_{n q_{h}}+n_{i} i_{q_{h}}=-\frac{1}{D_{i}} u_{q_{g} q_{g}} u_{q_{z} q_{z}} P_{q_{h}, i}\left(n_{i} u_{c c} u_{n n}+2 u_{n} u_{c c}-\frac{u_{c}^{2}}{n_{i}}\right)>0$

$q_{g} \frac{\partial g_{i}}{\partial \alpha}=-s_{n q_{g}}-n_{i} i_{q_{g}}=-\frac{1}{D_{i}} u_{q_{h} q_{h}} u_{q_{z} q_{z}} P_{q_{g}, i}\left(n_{i} u_{c c} u_{n n}+2 u_{n} u_{c c}-\frac{u_{c}^{2}}{n_{i}}\right)>0$

Regarding the effects of an increase of the child benefit rate on the inputs of children's quality, parental time and child care, the substitution effects of the marginal cost of quantity on the demand for quality are negative. As child benefits have no direct effect on the quality of children, the ratio of quality and quantity will fall since the relative price of quality to quantity rises with $\alpha$. This can be illustrated by a comparison of the net price of children with respect to the number of children in (5) and to the quality of children in (6) and (7). The price for quality of children is not affected by changes in the child benefit rate. Therefore, the change of the relative price in favor of the quantity of children reduces the parental time and the child care and, hence, the quality of children. However, the positive income effect dominates this substitution effect.

The size of the effect of an increase in $\alpha$ on parental time in (10) is driven by the marginal net price of parental time, $P_{q_{h},}$, and is thus larger for high income families. The size of the effect on the time the children spend in external child care in (11) depends on the marginal price for external child care, $P_{q_{g}, i}$, which is independent of the wage income. Hence, child benefits have a stronger impact on high income earners to stay home with the children than on low income earners whereas the effect on the demand for external child care is the same. Thus, the labor supply of the high income secondary earner decreases by more.

Proposition 1: Increasing the child benefit rate encourages fertility and the demand for external child care while it discourages the secondary earner's labor supply. The effects on fertility and labor supply are larger for high income secondary earners. As child benefits only have a direct effect on the quantity of children, an increase in the child benefit rate leads to a decrease in the ratio of quality and quantity of children.

The other two policy instruments have no clear effect on fertility. The absolute effect of an increase of subsidy for bought-in child care, $\beta$, depends on the price elasticity of demand for external child care time, that is $\left(1+\frac{g_{i} u_{q_{g} q_{g}}}{u_{q_{g}}}\right)=\left(1+\frac{1}{\varepsilon_{g, i}}\right)$, where $\varepsilon_{g, i} \equiv \frac{d g_{i}}{d P_{q_{g}, i}} \frac{P_{q_{g}, i}}{g_{i}}<0$. If family $i$ 's demand for external child care time is inelastic, $\varepsilon_{g, i}>-1$, fertility increases with a higher subsidy, and vice versa. 


$$
\frac{\partial n_{i}}{\partial \beta}=-\pi\left(g_{i} s_{n n}+n_{i} s_{q_{g} n}+g_{i} n_{i} i_{n}\right)=\frac{\pi}{D_{i}} u_{q_{g}} u_{q_{h} q_{h}} u_{q_{z} q_{z}}\left(u_{c}-n_{i} u_{c c} P_{n, i}\right)\left(1+\frac{1}{\varepsilon_{g, i}}\right) \gtreqless 0
$$

The size of the effect on fertility in (12) rises with the price of external child care, $\pi$, the number of children of family $i, n_{i}$, and the marginal price for quantity, $P_{n, i}$. A higher $\beta$ decreases the net price of a child, $P_{n, i}$, which induces a positive income effect, $-\pi g_{i} n_{i} i_{n}$, and a positive substitution effect on the demand for the number of children, $-\pi g_{i} s_{n n}$. Both effects exceed the negative substitution effect of the marginal cost of bought-in child care on the demand for quantity, $-\pi n_{i} s_{q_{g} n}$, if $\varepsilon_{g, i}>-1$ holds. For families with $\varepsilon_{g, i}<-1$, the negative substitution effect dominates the other two effects and the total effect on fertility is thus negative. This negative substitution effect arises because a higher $\beta$ decreases the net price of a child less than the net price of external child care. Thus the relative price between the quantity of children and child care increases so that the family decides for fewer children relative to the demand for child care.

The absolute effect of an increase of the parental leave payments, $\gamma$, is similar to the effect of the subsidy. The difference is that now the size of the effect increases in the secondary earner's net wage rate, $\widehat{w}_{i}$, and the direction of the effect on fertility depends on the elasticity of demand for parental child care time, that is $\left(1+\frac{h_{i} u_{q_{h} q_{h}}}{u_{q_{h}}}\right) \equiv\left(1+\frac{1}{\varepsilon_{h, i}}\right)$, with $\varepsilon_{h, i}=$ $\frac{d h_{i}}{d P_{q_{h}, i}} \frac{P_{q_{h}, i}}{h_{i}}<0$. Only for families whose demand for parental child care time is inelastic, that is $\varepsilon_{h, i}>-1$, parental leave payments have a positive impact on the number of children. The impact of an increase of the parental leave payment on fertility is thus ambiguous

$$
\frac{\partial n_{i}}{\partial \gamma}=-\widehat{w}_{i}\left(h_{i} s_{n n}-n_{i} s_{q_{h} n}+h_{i} n_{i} i_{n}\right)=\frac{\widehat{w}_{i}}{D_{i}} u_{q_{h}} u_{q_{g} q_{g}} u_{q_{z} q_{z}}\left(u_{c}-n_{i} u_{c c} P_{n, i}\right)\left(1+\frac{1}{\varepsilon_{h, i}}\right) \gtreqless 0
$$

The size of this effect depends on the secondary earner's net wage rate $\widehat{w}_{i}$. If $\varepsilon_{h, i}>-1$ holds, the positive income effect, $-\widehat{w}_{i} h_{i} n_{i} i_{n}$, and the positive substitution effect of the marginal price of quantity on the demand for children, $-\widehat{w}_{i} h_{i} s_{n n}$, exceed the negative substitution effect of the marginal costs of parental child care time on the demand for children, $-\widehat{w}_{i} n_{i} s_{q_{h} n}$, and the total effect on fertility is thus positive. The last substitution effect is negative because higher parental leave payments reduce the opportunity costs of staying home with the children.

Considering the effects on the time management, we find the following pattern of both the subsidy for external child care and the parental leave payments. Each instrument increases the 
demand for that type of child care (parental or external) the marginal price of which it directly lowers. The indirect effect on the complementing type of child care is ambiguous.

The effect of an increase of $\beta$ is ambiguous with respect to parental time and positive for the demand of time children spend in external child care.

$$
\begin{gathered}
q_{h} \frac{\partial h_{i}}{\partial \beta}=\pi\left(g_{i} s_{n q_{h}}+n_{i} s_{q_{g} q_{h}}+g_{i} n_{i} i_{q_{h}}\right) \\
=-\frac{\pi}{D_{i}} u_{q_{g}} u_{q_{z} q_{z}} P_{q_{h}, i}\left(n_{i} u_{c c} u_{n n}+2 u_{n} u_{c c}-\frac{u_{c}^{2}}{n_{i}}\right)\left(1+\frac{1}{\varepsilon_{g, i}}\right) \gtreqless 0 \\
q_{g} \frac{\partial g_{i}}{\partial \beta}=-\pi\left(g_{i} s_{n q_{g}}+n_{i} s_{q_{g} q_{g}}+g_{i} n_{i} i_{q_{g}}\right) \\
=\frac{\pi}{D_{i}}\left[( u _ { c } u _ { q _ { z } q _ { z } } P _ { q _ { h } , i } ^ { 2 } + u _ { c } u _ { q _ { h } q _ { h } } P _ { q _ { z } , i } ^ { 2 } - g _ { i } u _ { q _ { h } q _ { h } } u _ { q _ { z } q _ { z } } P _ { q _ { g } , i } ) \left(n_{i} u_{c c} u_{n n}\right.\right. \\
\left.\left.+2 u_{n} u_{c c}-\frac{u_{c}^{2}}{n_{i}}\right)+n_{i} u_{c} u_{q_{h} q_{h}} u_{q_{z} q_{z}}\left(u_{c c} P_{n, i}^{2}+u_{n n}\right)\right]>0
\end{gathered}
$$

The effect of an increase of the subsidy on external child care on parental time in equation (12) is positive if $\varepsilon_{g, i}>-1$ and negative if $\varepsilon_{g, i}<-1$ holds.

Both of the substitution effects in (14) are negative for the following reason: A higher $\beta$ decreases the price of a child but not the opportunity cost of parental time. Hence, the quantity of children becomes relatively less costly than increasing the quality by staying at home. Furthermore, as the net cost of external child care decreases it becomes relatively more attractive to buy more child care on the market than to provide own parental time for the children. However, the positive income effect, $\pi g_{i} n_{i} i_{q_{h}}$, exceeds the negative substitution effects for families with $\varepsilon_{g, i}>-1$. As before, the size of the total effect increases with the secondary earner's income.

Regarding the demand for external child care in (15), both the income effect, $-\pi g_{i} n_{i} i_{q_{g}}$, and the own substitution effect of the marginal costs of bought-in child care on the time the child spends in external child care, $-\pi n_{i} s_{q_{g} q_{g}}$, are positive and they exceed the negative substitution effect of the marginal cost of quantity on the time the child spends in child care, $-\pi g_{i} s_{n q_{g}}$ 
The overall effect of an increase of parental leave payments $\gamma$ on parental time is positive while the effect on external child care time is ambiguous.

$$
\begin{aligned}
q_{h} \frac{\partial h_{i}}{\partial \gamma}=\widehat{w}_{i}\left(h_{i} s_{n q_{h}}-n_{i} s_{q_{h} q_{h}}+h_{i} n_{i} i_{q_{h}}\right) & \\
= & \frac{\widehat{w}_{i}}{D_{i}}\left[( u _ { c } u _ { q _ { g } q _ { g } } P _ { q _ { z } , i } ^ { 2 } + u _ { q _ { c } } u _ { q _ { z } q _ { z } } P _ { q _ { g } , i } ^ { 2 } - h _ { i } u _ { q _ { g } q _ { g } } u _ { q _ { z } q _ { z } } P _ { q _ { h } , i } ) \left(n_{i} u_{c c} u_{n n}\right.\right. \\
& \left.\left.+2 u_{n} u_{c c}-\frac{u_{c}^{2}}{n_{i}}\right)+n_{i} u_{c} u_{q_{g} q_{g}} u_{q_{z} q_{z}}\left(u_{c c} P_{n, i}^{2}+u_{n n}\right)\right]>0 \\
q_{g} \frac{\partial g_{i}}{\partial \gamma}=-\widehat{w}_{i}( & \left.h_{i} s_{n q_{g}}-n_{i} s_{q_{h} q_{g}}+h_{i} n_{i} i_{q_{g}}\right) \\
= & -\frac{\widehat{w}_{i}}{D_{i}} u_{q_{h}} u_{q_{z} q_{z}} P_{q_{g}, i}\left(n_{i} u_{c c} u_{n n}+2 u_{n} u_{c c}-\frac{u_{c}^{2}}{n_{i}}\right)\left(1+\frac{1}{\varepsilon_{h, i}}\right) \gtreqless 0
\end{aligned}
$$

Concerning parental time in (16), the positive income effect, $\widehat{w}_{i} h_{i} n_{i} i_{q_{h}}$, and the positive own substitution effect of the marginal costs of parental time on the demand for parental time, $-\widehat{w}_{i} n_{i} s_{q_{h} q_{h}}$, exceed the negative substitution effect of the marginal price for quantity on the demand for parental time, $\widehat{w}_{i} h_{i} s_{n q_{h}}$. Parental leave payments work like an implicit tax on continued work. Therefore, they set incentives to decrease labor supply. At the same time they improve the quality of the children. Since the net price of the number of children decreases by less than the net price of parental time, the quality of children increases relatively to the quantity. Regarding the time the children spend at external child care in (17) on the other hand, the two substitution effects are negative and only fall short of the positive income effect, $-\widehat{w}_{i} h_{i} n_{i} i_{q_{g}}$, if $\varepsilon_{h, i}>-1$ holds. For family $i$ with $\varepsilon_{h, i}<-1$, the total effect on $g_{i}$ is thus negative.

The more the government subsidizes external or parental child care, the more family $i$ takes advantage of the subsidized type of child care and the share of this type of child care in total time spent with the children increases disproportionately.

Proposition 2: A subsidy for external child care and parental leave payments have similar effects on fertility and the use of time for child care. Both policy instruments have positive effects on fertility only for families whose demand for external child care - in the case of the subsidy - or whose demand for parental child care time - in the case of leave payments - is inelastic. The subsidy increases the demand for external child care for all families, while the leave payments increase the parental time (reduce the secondary earner's labor supply) for all families. Parental leave payments reduce the opportunity cost of staying home so that they work like an implicit tax on continued work. 


\subsection{Differential effects}

Now we compare mutually the effectiveness of the three policy instruments in raising the number of children and increasing the secondary earner's labor supply. We consider a budget neutral substitution of two instruments in order to determine the relative size of the effect of each instrument. The government's budget is given by:

$$
t(Y+\bar{w} L)=\alpha \bar{n}+\beta \pi \bar{g} \bar{n}+\gamma \overline{\widehat{w}} \bar{h} \bar{n}
$$

where $\bar{n}, \bar{g}, \bar{h}, \bar{w}$, and $\overline{\widehat{w}}$ represent the average number of children, use of external child care, parental child care, wage and net wage respectively. In the following we consider first average families, i.e. families with average wage income and average demand. This is also the case of identical families. Second, we consider re-distributional effects and families who are heterogeneous in wage earnings and demand. We differentiate between two groups of families in the benefit system: families who are initially, i.e. before the reform, net contributors or net receivers of the tax-financed family policies.

Looking at first at an exchange of child benefits and subsidies for bought-in child care, the budget keeps constant if $d \alpha=-\pi \bar{g} d \beta$. Here we distinguish ceteris paribus between two groups of families, those who initially consume below average, that is $g_{i}<\bar{g}$, and those who

initially consume above average external child care, that is $g_{i}>\bar{g}$. The families of the first group are net contributors to the policy change while families of the second group are net recipients. As both the child benefit and the subsidy for external child care depend on the number of children, there is no redistribution with respect to the number of children.

An increase of the subsidy, $\beta$, accompanied by a reduction of the child benefit, $\alpha$, so as to keep the budget constant has the following differential effects. Taking account of equations (9) and (12), the effect on the number of children, $n_{i}$, is given by:

$$
\begin{aligned}
\left.\frac{d n_{i}}{d \beta}\right|_{d \alpha=-\pi \bar{g} d \beta} & =\frac{\partial n_{i}}{\partial \beta} d \beta+\frac{\partial n_{i}}{\partial \alpha} d \alpha=-\pi\left[\left(s_{n n}+n_{i} i_{n}\right)\left(g_{i}-\bar{g}\right)+n_{i} s_{q_{g} n}\right] \\
& =\frac{\pi}{D_{i}} u_{q_{g}} u_{q_{h} q_{h}} u_{q_{z} q_{z}}\left(u_{c}-n_{i} u_{c c} P_{n, i}\right)\left[1+\frac{\left(g_{i}-\bar{g}\right) u_{q_{g} q_{g}}}{u_{q_{g}}}\right]
\end{aligned}
$$


Combining equations (10) and (14) gives the differential effect for the secondary earner's parental time, $h_{i}$ :

$$
\begin{aligned}
\left.\frac{d h_{i}}{d \beta}\right|_{d \alpha=-\pi \bar{g} d \beta} & =\frac{\partial h_{i}}{\partial \beta} d \beta+\frac{\partial h_{i}}{\partial \alpha} d \alpha=\pi\left[\left(s_{n q_{h}}+n_{i} i_{q_{h}}\right)\left(g_{i}-\bar{g}\right)+n_{i} s_{q_{g} q_{h}}\right] \\
& =-\frac{\pi}{D_{i}} u_{q_{g}} u_{q_{z} q_{z}} P_{q_{h}, i}\left(n_{i} u_{c c} u_{n n}+2 u_{n} u_{c c}-\frac{u_{c}^{2}}{n_{i}}\right)\left[1+\frac{\left(g_{i}-\bar{g}\right) u_{q_{g} q_{g}}}{u_{q_{g}}}\right]
\end{aligned}
$$

With equations (11) and (15) a budget-neutral comparison of the effects of the two policy instruments on the demand for external child care yields:

$$
\begin{aligned}
\left.\frac{d g_{i}}{d \beta}\right|_{d \alpha=-\pi \bar{g} d \beta} & =\frac{\partial g_{i}}{\partial \beta} d \beta+\frac{\partial g_{i}}{\partial \alpha} d \alpha=-\pi\left[\left(s_{n q_{g}}+n_{i} i_{q_{g}}\right)\left(g_{i}-\bar{g}\right)+n_{i} s_{q_{g} q_{g}}\right] \\
& =-\frac{\pi}{D_{i}}\left\{( n _ { i } u _ { c c } u _ { n n } + 2 u _ { n } u _ { c c } - \frac { u _ { c } ^ { 2 } } { n _ { i } } ) \left[u_{q_{h} q_{h}} u_{q_{z} q_{z}} P_{q_{g}, i}\left(g_{i}-\bar{g}\right)\right.\right. \\
& \left.\left.-u_{c} u_{q_{z} q_{z}} P_{q_{h}, i}^{2}-u_{c} u_{q_{h} q_{h}} P_{q_{z}, i}^{2}\right]-n_{i} u_{c} u_{q_{h} q_{h}} u_{q_{z} q_{z}}\left(u_{c c} P_{n, i}^{2}+u_{n n}\right)\right\}
\end{aligned}
$$

From the three derivations (19), (20) and (21) we can infer the following results. In the case of identical families (or families with average demand for child care), $g_{i}=\bar{g}$ for all $i$, a reduction of child benefits in favor of higher subsidies for child care decreases fertility and parental time and increases the demand for external child care. In case of a subsidy for external child care the money is bound to this service whereas the child benefits are paid unconditional. Therefore, an increase in $\beta$ has a smaller impact on fertility than an increase of $\alpha$, and it leads to a substitution of parental child care by external child care so that the secondary earner's labor supply increases.

For heterogeneous families whose initial demand for external child care is lower than average, $g_{i}<\bar{g}$, again the subsidy for child care has a weaker effect on fertility and on parental child care than child benefits. The reason is that this policy change increases the price of a child $P_{n, i}$ from (5) and decreases the price of external child care $P_{q_{g}, i}$ from (7) for all families with $g_{i}<\bar{g}$ inducing the substitutional effect mentioned above. However, this is the group of families who are net contributors to the policy change. If the financial net burden of the family is high enough, $g_{i} \ll \bar{g}$, the demand for external child care may even diminish with this policy change.

The effect of the budget neutral increase of $\beta$ for all families with $g_{i}>\bar{g}$ is straightforward with respect to the demand for external child care. For those net recipients of the subsidy the policy change leads to more external child care. The effects are ambiguous for fertility 
behavior and parental child care. They depend on family $i$ 's price elasticity of the demand for external child care. The policy change decreases the price of a child $P_{n, i}$ and, at the same time, the price of external child care $P_{q_{g}, i}$ goes down. If the family's demand is inelastic, $\varepsilon_{g, i}>-1$, the last price relief increases external child care only to a small amount but transmits to a higher fertility and even higher parental child care.

Hence, supporting the demand for child care is only a more promising way of fostering fertility than child benefits for net recipients if their demand for external child care is inelastic. At the same time it decreases the labor supply of the secondary earner. For all families, the effect increases with $P_{n, i}$ and it therefore depends on the secondary earner's income.

Combining our results from (20) and (21), we can conclude that for most families a higher subsidy of external child care and a budget-neutral reduction of child benefits leads to an increase in bought-in child care and a decrease of parental child care. The last effect is equivalent to an increase in the secondary earner's employment rate. However, at the same time the incentives for having children are negative.

The same policy exchange also leads to both less parental and child-specific consumption for net contributors while the effect is ambiguous for the others (see Appendix B). This negative effect on consumption can be explained by the fact that in the case of the subsidy the money is bound to external child care and thus does not benefit consumption in the way the child benefit does.

Proposition 3: A budget-neutral increase of a subsidy for external child care accompanied by a decrease of child benefits has a negative effect on fertility and a positive effect on the secondary earner's labor supply for family $i$ consuming $g_{i} \leq \bar{g}$. The same policy exchange leads to an increase in the demand for external child care for families with $g_{i}>\bar{g}$.

Comparing child benefits and the rate of parental leave payments, a budget neutral substitution requires $d \alpha=-\overline{\widehat{w}} \bar{h} d \gamma$. In this case we have to again differentiate between two groups of families: Net contributors, that is $\widehat{w}_{i} h_{i}<\overline{\widehat{w}} \bar{h}$, and net recipients, that is $\widehat{w}_{i} h_{i}>\overline{\widehat{w}} \bar{h}$, of the policy change. As both the child benefit and the parental leave payments depend on the number of children, there is no redistribution with respect to the number of children.

Taking account of (9) and (13), the effect of increasing the parental leave payments on the number of children is given by: 


$$
\begin{aligned}
\left.\frac{d n_{i}}{d \gamma}\right|_{d \alpha=-\bar{w} \bar{h} d \gamma} & =\frac{\partial n_{i}}{\partial \gamma} d \gamma+\frac{\partial n_{i}}{\partial \alpha} d \alpha=\left(\overline{\widehat{w}} \bar{h}-\widehat{w}_{i} h_{i}\right)\left(s_{n n}+n_{i} i_{n}\right)+\widehat{w}_{i} n_{i} s_{q_{h} n} \\
& =\frac{\widehat{w}_{i}}{D_{i}} u_{q_{h}} u_{q_{g} q_{g}} u_{q_{z} q_{z}}\left(u_{c}-n_{i} u_{c c} P_{n, i}\right)\left[1+\frac{\left(\widehat{w}_{i} h_{i}-\widehat{\widehat{w}} \bar{h}\right) u_{q_{h} q_{h}}}{\widehat{w}_{i} u_{q_{h}}}\right]
\end{aligned}
$$

Looking at the effect of the policy exchange on the time parents spent with their children at home, $h_{i}$, we derive from (10) and (16):

$$
\begin{aligned}
\left.\frac{d h_{i}}{d \gamma}\right|_{d \alpha=-\bar{w} \bar{h} d \gamma} & =\frac{\partial h_{i}}{\partial \gamma} d \gamma+\frac{\partial h_{i}}{\partial \alpha} d \alpha=-\left(\overline{\widehat{w}} \bar{h}-\widehat{w}_{i} h_{i}\right)\left(s_{n q_{h}}+n_{i} i_{q_{h}}\right)-\widehat{w}_{i} n_{i} s_{q_{h} q_{h}} \\
& =-\frac{1}{D_{i}}\left\{( n _ { i } u _ { c c } u _ { n n } + 2 u _ { n } u _ { c c } - \frac { u _ { c } ^ { 2 } } { n _ { i } } ) \left[\left(\widehat{w}_{i} h_{i}-\overline{\widehat{w}} \bar{h}\right) u_{q_{g} q_{g}} u_{q_{z} q_{z}} P_{q_{h}, i}\right.\right. \\
& \left.\left.-\widehat{w}_{i} u_{c}\left(u_{q_{g} q_{g}} P_{q_{z}, i}^{2}+u_{q_{z} q_{z}} P_{q_{g}, i}^{2}\right)\right]-\widehat{w}_{i} n_{i} u_{c} u_{q_{g} q_{g}} u_{q_{z} q_{z}}\left(u_{c c} P_{n, i}^{2}+u_{n n}\right)\right\}
\end{aligned}
$$

And the effect of the budget-neutral exchange of instruments on the time spend at external child care, $g_{i}$, follows from (11) and (17):

$$
\begin{aligned}
\left.\frac{d g_{i}}{d \gamma}\right|_{d \alpha=-\bar{w} \bar{h} d \gamma} & =\frac{\partial g_{i}}{\partial \gamma} d \gamma+\frac{\partial g_{i}}{\partial \alpha} d \alpha=\left(\overline{\widehat{w}} \bar{h}-\widehat{w}_{i} h_{i}\right)\left(s_{n q_{g}}+n_{i} i_{q_{g}}\right)+\widehat{w}_{i} n_{i} s_{q_{h} q_{g}} \\
& =-\frac{\widehat{w}_{i}}{D_{i}} u_{q_{h}} u_{q_{z} q_{z}} P_{q_{g}, i}\left(n_{i} u_{c c} u_{n n}+2 u_{n} u_{c c}-\frac{u_{c}^{2}}{n_{i}}\right)\left[1+\frac{\left(\widehat{w}_{i} h_{i}-\overline{\widehat{w}} \bar{h}\right) u_{q_{h} q_{h}}}{\widehat{w}_{i} u_{q_{h}}}\right]
\end{aligned}
$$

The impact of a policy reform with higher parental leave payments and a budget-neutral decrease in child benefits can be derived from (22), (23) and (24). For identical (or average) families with $\widehat{w}_{i}=\overline{\widehat{w}}$ and $h_{i}=\bar{h}$ the incentives for children and for the demand for external child care are negative while incentives for parental time with the children are positive. This means the reverse policy may generate desired incentives for family behavior. An increase of child benefits at the cost of lower parental leave payments will raise the number of children and the demand for external child care and, at the same time, it will stimulate the labor supply of parents. The reason is that the child benefits have directly positive (income) effects on the number of children and the demand for external child care. And the budget-neutral decrease of leave payments reduces the implicit tax on work. Hence, if the positive effect of external child care on the quality of children is equal or higher than the positive effect of parental child care a policy reform with higher child benefits and lower parental leave payments may support fertility and parental employment without lowering the quality of children. Such a policy would qualify as a way to balance family and work. 
The results are not clear-cut when we consider heterogeneous families with differing wages. The impact of higher leave payments at the cost of lower child benefits on fertility is negative for secondary earners whose income weighted parental time is smaller than the average, that is $\widehat{w}_{i} h_{i}<\bar{w} \bar{h}$. In this case the parental leave payment therefore has a weaker effect on fertility than child benefits. Hence, for families with low opportunity costs of staying home and taking care of their children, a child benefit is a more effective instrument to set incentives for children than a parental leave payment. At the same time the policy leads to a decrease of the demand for external child care. However, the effect on parental child care is ambiguous. The reason is that this group of families is net contributor to the policy change and the quantity as well as the quality of the children may be effectively reduced.

For secondary earners with above-average initial opportunity costs, $\widehat{w}_{i} h_{i}>\overline{\widehat{w}} \bar{h}$, the policy reform induces a higher demand for time spent with the children and, hence, a lower labor supply. So the net recipients of this policy reduce employment. The effects on the number of children and external child care depend on the price elasticity of the demand for parental child care time. For family $i$ having high initial opportunity costs $\widehat{w}_{i} h_{i} \gg \overline{\widehat{w}} \bar{h}$ such that $\left[\left(\widehat{w}_{i} h_{i}-\right.\right.$ $\left.\overline{\widehat{w}} \bar{h}) u_{q_{h} q_{h}}+\widehat{w}_{i} u_{q_{h}}\right]<0$, the budget-neutral increase of parental leave payments leads to an increase in both fertility and the demand for external child care. Net recipients of the policy with high opportunity costs of staying home therefore may benefit from an increase in $\gamma$ to an extent that they also raise their demand for external child care and for children.

Combining our results from (23) and (24), we can conclude that the policy exchange has a negative effect on the demand of external child care for families with $\widehat{w}_{i} h_{i} \leq \overline{\widehat{w}} \bar{h}$ and a positive effect on parental child care for secondary earners with $\widehat{w}_{i} h_{i} \geq \overline{\widehat{w}} \bar{h}$. Only families who initially have very large opportunity costs of staying at home may use the additional parental leave payments to consume more external child care.

The policy exchange of child benefits and parental leave payments by $d \alpha=-\widehat{\widehat{w}} h d \gamma$ leads also to less parental and child-specific consumption for families with $\bar{w} \bar{h}>\widehat{w}_{i} h_{i}$ (see Appendix B). This reduction in parental and child-specific consumption can be explained by the increased parental child care time and thus reduced family income.

Proposition 4: An increase of parental leave payments accompanied by a budget-neutral reduction of child benefits leads to a decrease (increase) in fertility and a lower (higher) demand for external child care for secondary earners with $\widehat{w}_{i} h_{i} \leq \overline{\widehat{w}} \bar{h}\left(\widehat{w}_{i} h_{i} \gg \overline{\widehat{w}} \bar{h}\right)$. The same policy exchange leads to an increase in parental child care for families with $\widehat{w}_{i} h_{i}>$ $\overline{\widehat{w}} \bar{h}$. 
When comparing the effects of an increase of the subsidy for external child care and a budgetneutral reduction of parental leave payments such that $d \gamma=-\frac{\pi \bar{g}}{\overline{\bar{w}} \bar{h}} d \beta$ we obtain the fertility change with (12) and (13):

$$
\begin{aligned}
\left.\frac{d n_{i}}{d \beta}\right|_{d \gamma=-\frac{\pi \bar{g}}{\bar{w} \bar{h}} d \beta} & =\frac{\partial n_{i}}{\partial \beta} d \beta+\frac{\partial n_{i}}{\partial \gamma} d \gamma \\
& =-\pi\left(g_{i}-\frac{\widehat{w}_{i} h_{i}}{\widehat{\widehat{w}} \bar{h}} \bar{g}\right)\left(s_{n n}+n_{i} i_{n}\right)-\pi n_{i}\left(s_{q_{g} n}+\frac{\bar{g} \widehat{w}_{i}}{\bar{h}} s_{q_{h} n}\right) \\
& =-\frac{\pi}{D_{i}} u_{q_{z} q_{z}}\left(n_{i} u_{c c} P_{n, i}-u_{c}\right)\left[\left(g_{i}-\frac{\widehat{w}_{i} h_{i}}{\widehat{\widehat{w}} \bar{h}} \bar{g}\right) u_{q_{h} q_{h}} u_{q_{g} q_{g}}\right. \\
& \left.+u_{c}\left(u_{q_{h} q_{h}} P_{q_{g}, i}-\frac{\bar{g}}{\bar{h}} \frac{\widehat{w}_{i}}{\widehat{\widehat{w}}} u_{q_{g} q_{g}} P_{q_{h}, i}\right)\right]
\end{aligned}
$$

From equations (14) and (16) we derive the impact on parental child care:

$$
\begin{aligned}
\left.\frac{d h_{i}}{d \beta}\right|_{d \gamma=-\frac{\pi \bar{g}}{\bar{w}} d \beta} & =\frac{\partial h_{i}}{\partial \beta} d \beta+\frac{\partial h_{i}}{\partial \gamma} d \gamma \\
& =\pi\left(g_{i}-\frac{\widehat{w}_{i} h_{i}}{\widehat{\widehat{w}} \bar{h}} \bar{g}\right)\left(s_{n q_{h}}+n_{i} i_{q_{h}}\right)+\pi n_{i}\left(s_{q_{g} q_{h}}+\frac{\bar{g}}{\bar{h}} \frac{\widehat{w}_{i}}{\widehat{\widehat{w}}} s_{q_{h} q_{h}}\right) \\
& =-\frac{\pi}{D_{i}}\left\{( n _ { i } u _ { c c } u _ { n n } + 2 u _ { n } u _ { c c } - \frac { u _ { c } ^ { 2 } } { n _ { i } } ) \left[\left(g_{i}-\frac{\widehat{w}_{i} h_{i}}{\overline{\widehat{w}} \bar{h}} \bar{g}\right) u_{q_{g} q_{g}} u_{q_{z} q_{z}} P_{q_{h}, i}\right.\right. \\
& \left.+u_{c} u_{q_{z} q_{z}} P_{q_{h}, i}^{2}+\frac{\bar{g}}{\bar{h}} \frac{\widehat{w}_{i}}{\widehat{\widehat{w}}} u_{c}\left(u_{q_{g} q_{g}} P_{q_{z}, i}^{2}+u_{q_{z} q_{z}} P_{q_{g}, i}^{2}\right)\right] \\
& \left.+\frac{\bar{g} \widehat{w}_{i}}{\bar{h}} \frac{\widehat{w}_{\bar{w}}}{\widehat{\widehat{w}}} n_{i} u_{q_{g} q_{g}} u_{q_{z} q_{z}}\left(u_{c c} P_{n, i}^{2}+u_{n n}\right)\right\}
\end{aligned}
$$

And the effect on external child care follows from (15) and (17):

$$
\begin{aligned}
\left.\frac{d g_{i}}{d \beta}\right|_{d \gamma=-\frac{\pi \bar{g}}{\bar{w}} d \beta} & =\frac{\partial g_{i}}{\partial \beta} d \beta+\frac{\partial g_{i}}{\partial \gamma} d \gamma \\
& =-\pi\left(g_{i}-\frac{\widehat{w}_{i} h_{i}}{\widehat{\widehat{w}} \bar{h}} \bar{g}\right)\left(s_{n q_{g}}+n_{i} i_{q_{g}}\right)-\pi n_{i}\left(s_{q_{g} q_{g}}+\frac{\bar{g}}{\bar{h}} \frac{\widehat{w}_{i}}{\widehat{\widehat{w}}} s_{q_{h} q_{g}}\right) \\
& =-\frac{\pi}{D_{i}}\left\{( n _ { i } u _ { c c } u _ { n n } + 2 u _ { n } u _ { c c } - \frac { u _ { c } ^ { 2 } } { n _ { i } } ) \left[\left(g_{i}-\frac{\widehat{w}_{i} h_{i}}{\widehat{\widehat{w}} \bar{h}} \bar{g}\right) u_{q_{h} q_{h}} u_{q_{z} q_{z}} P_{q_{g}, i}\right.\right. \\
& \left.-u_{c}\left(u_{q_{z} q_{z}} P_{q_{h}, i}^{2}+u_{q_{h} q_{h}} P_{q_{z}, i}^{2}+\frac{\bar{g}}{\bar{h}} \frac{\widehat{w}_{i}}{\widehat{\widehat{w}}} u_{q_{z} q_{z}} P_{q_{g}, i}^{2}\right)\right] \\
& \left.-n_{i} u_{c} u_{q_{h} q_{h}} u_{q_{z} q_{z}}\left(u_{c c} P_{n, i}^{2}+u_{n n}\right)\right\}
\end{aligned}
$$

For identical families $\left(\widehat{w}_{i}=\overline{\widehat{w}}, g_{i}=\bar{g}, h_{i}=\bar{h}\right)$ we get the following results. Given a policy change that shifts transfers from leave payments to subsidies for external child care it is hardly surprising that the demand for external child care increases while the parental time 
with children at home will be reduced (see (26) and (27)). Whether the subsidy of external child care or the parental leave payments are more effective in fostering fertility depends on the elasticities of demand for external child care and parental child care (see (25)). The family policy instrument that supports the child care (external or parental) with the less elastic response is more effective in fostering fertility. E.g. if the demand for external child care responds less elastic to changes in the price than the willingness of parents to stay at home which means the (negative) price elasticity of external child care is larger than the elasticity of parental child care, that is $\varepsilon_{g}>\varepsilon_{h}{ }^{1}$ - we find that the subsidy for external child care $\beta$ sets better incentives for children than a parental leave payment at rate $\gamma$. In summary, a policy change of higher subsidies for external child care and lower leave payments increases the demand for external child care and the employment of secondary earners. At the same time it can set positive incentives for having children if the demand for external child care is not too elastic.

For heterogeneous families the response to this policy change depends on a family's demand for external child care relative to average demand and the relative opportunity costs of staying at home, that is the relation between $\frac{g_{i}}{\bar{g}}$ and $\frac{\widehat{w}_{i} h_{i}}{\bar{w} \bar{h}}$. The budget-neutral increase of the subsidy for external child care has a negative effect on parental child care for all secondary earners whose relative demand for external child care is smaller than the relative opportunity costs of staying at home, that is $\frac{g_{i}}{\bar{g}}<\frac{\widehat{w}_{i} h_{i}}{\bar{w} \bar{h}}$. Hence, this group's labor supply will increase due to the policy exchange. Furthermore, the demand for external child care increases in all families with $\frac{g_{i}}{\bar{g}}>\frac{\widehat{w}_{i} h_{i}}{\bar{w} \bar{h}}$. For this group the effect on parental child care is also likely to be negative. Combined with the result for the effect of the budget-neutral policy exchange on $g_{i}$ in (27), we find that the ratio of external to parental child care will increase for all families. Increasing the subsidy for external child care has thus a positive effect on secondary earner $i$ 's labor supply.

The effect of the budget-neutral policy exchange on fertility is ambiguous and depends next to the relation between $\frac{g_{i}}{\bar{g}}$ and $\frac{\widehat{w}_{i} h_{i}}{\bar{w} \bar{h}}$ also on the relation between the price elasticity of external child care and the income weighted elasticity of parental child care, that is $\frac{u_{q_{g} q_{g}}}{u_{q_{g}}} \bar{g}$ and $\frac{u_{q_{h} q_{h}}}{u_{q_{h}}} \frac{\bar{w} \bar{h}}{\widehat{w}_{i}}$. The budget-neutral increase of the subsidy for external childcare has a positive effect on

\footnotetext{
${ }^{1}$ This condition is equivalent to the requirement that the elasticity of marginal utility w.r.t. $h$ is larger than w.r.t. $g$, that is $\frac{u_{q_{h} q_{h}}}{u_{q_{h}}} \bar{h}>\frac{u_{q_{g} q_{g}}}{u_{q_{g}}} \bar{g}$.
} 
fertility for all families with $\frac{g_{i}}{\bar{g}}>\frac{\widehat{w}_{i} h_{i}}{\bar{w} \bar{h}}$ whose price elasticity of external child care is larger than the income weighted elasticity of parental child care, that is $\varepsilon_{g}>\frac{\widehat{w}_{i}}{\overline{\widehat{w}}} \varepsilon_{h}$.

The differential effects on parent's and children's consumption are again shown in Appendix B.

Proposition 5: An increase of subsidies for external child care accompanied by a budgetneutral decrease of parental leave payments has a positive effect on the secondary earner's labor supply and the demand for external child care in the case of identical families. Moreover, fertility increases if the price elasticity of external child care is larger than the elasticity of parental time with the children, that is $\frac{u_{q_{h} q_{h}}}{u_{q_{h}}}>\frac{u_{q_{g} q_{g}}}{u_{q_{g}}} \bar{g}$. In the case of heterogeneous families the same budget-neutral exchange leads to an increase in the demand for external child care for all families whose relative demand for external child care is larger than the relative opportunity costs of staying at home, that is $\frac{g_{i}}{\bar{g}}>\frac{\widehat{w}_{i} h_{i}}{\overline{\widehat{w}} \bar{h}}$. Parental child care decreases in all families with $\frac{g_{i}}{\bar{g}}<\frac{\widehat{w}_{i} h_{i}}{\widehat{\widehat{w}} \bar{h}}$.

\section{Welfare Analysis}

In the welfare analysis we analyze the differential impact of an exchange of family policy instruments on family $i$ 's utility. We dare to talk of family's utility or welfare because the quality function $q(h, g, z)$ can be taken as a utility of a child nested in the parents' utility function. Nevertheless the decisions which influence the utility of the children are taken by the parents. In the following we discuss in particular the redistribution effects of budgetneutral policy exchanges on different income groups. We assume that the benevolent government maximizes the household's indirect utility function subject $V(\alpha, \beta, \gamma)$ to the government's budget constraint in (18). The maximization problem can be written as:

$$
\begin{aligned}
\max _{\alpha, \beta, \gamma} V(\alpha, \beta, \gamma) & =u\left(c_{i}(\alpha, \beta, \gamma), n_{i}(\alpha, \beta, \gamma), q_{i}\left(h_{i}(\alpha, \beta, \gamma), g_{i}(\alpha, \beta, \gamma), z_{i}(\alpha, \beta, \gamma)\right)\right) \\
& +\mu[t(Y+\bar{w}(1-\bar{h}(\alpha, \beta, \gamma) \bar{n}(\alpha, \beta, \gamma)))-\alpha \bar{n}(\alpha, \beta, \gamma)-\beta \pi \bar{g}(\alpha, \beta, \gamma) \bar{n} \\
& -\gamma \overline{\widehat{w}} \bar{h}(\alpha, \beta, \gamma) \bar{n}(\alpha, \beta, \gamma)]
\end{aligned}
$$


The total derivative of $V(\alpha, \beta, \gamma)$ is then given by:

$$
\begin{aligned}
d V=\left\{\frac{\partial u}{\partial c_{i}} \frac{\partial c_{i}}{\partial \alpha}\right. & +\frac{\partial u}{\partial n_{i}} \frac{\partial n_{i}}{\partial \alpha}+\frac{\partial u}{\partial q_{h}} \frac{\partial h_{i}}{\partial \alpha}+\frac{\partial u}{\partial q_{g}} \frac{\partial g_{i}}{\partial \alpha}+\frac{\partial u}{\partial q_{z}} \frac{\partial z_{i}}{\partial \alpha} \\
& \left.-\mu\left[(t \bar{w}+\gamma \widehat{\widehat{w}})\left(\frac{\partial \bar{h}}{\partial \alpha} \bar{n}+\bar{h} \frac{\partial \bar{n}}{\partial \alpha}\right)+\bar{n}+\alpha \frac{\partial \bar{n}}{\partial \alpha}+\beta \pi\left(\frac{\partial \bar{g}}{\partial \alpha} \bar{n}+\bar{g} \frac{\partial \bar{n}}{\partial \alpha}\right)\right]\right\} d \alpha \\
& +\left\{\frac{\partial u}{\partial c_{i}} \frac{\partial c_{i}}{\partial \beta}+\frac{\partial u}{\partial n_{i}} \frac{\partial n_{i}}{\partial \beta}+\frac{\partial u}{\partial q_{h}} \frac{\partial h_{i}}{\partial \beta}+\frac{\partial u}{\partial q_{g}} \frac{\partial g_{i}}{\partial \beta}+\frac{\partial u}{\partial q_{z}} \frac{\partial z_{i}}{\partial \beta}\right. \\
& \left.-\mu\left[(t \bar{w}+\gamma \overline{\widehat{w}})\left(\frac{\partial \bar{h}}{\partial \beta} \bar{n}+\bar{h} \frac{\partial \bar{n}}{\partial \beta}\right)+\alpha \frac{\partial \bar{n}}{\partial \beta}+\pi \bar{g} \bar{n}+\beta \pi\left(\frac{\partial \bar{g}}{\partial \beta} \bar{n}+\bar{g} \frac{\partial \bar{n}}{\partial \beta}\right)\right]\right\} d \beta \\
& +\left\{\frac{\partial u}{\partial c_{i}} \frac{\partial c_{i}}{\partial \gamma}+\frac{\partial u}{\partial n_{i}} \frac{\partial n_{i}}{\partial \gamma}+\frac{\partial u}{\partial q_{h}} \frac{\partial h_{i}}{\partial \gamma}+\frac{\partial u}{\partial q_{g}} \frac{\partial g_{i}}{\partial \gamma}+\frac{\partial u}{\partial q_{z}} \frac{\partial z_{i}}{\partial \gamma}\right. \\
& \left.-\mu\left[(t \bar{w}+\gamma \bar{w})\left(\frac{\partial \bar{h}}{\partial \gamma} \bar{n}+\bar{h} \frac{\partial \bar{n}}{\partial \gamma}\right)+\alpha \frac{\partial \bar{n}}{\partial \gamma}+\beta \pi\left(\frac{\partial \bar{g}}{\partial \gamma} \bar{n}+\bar{g} \frac{\partial \bar{n}}{\partial \gamma}\right)+\bar{w} \bar{h} \bar{n}\right]\right\} d \gamma
\end{aligned}
$$

Using the comparative static results in (9)-(17) as well as the comparative static results for parental and child-specific consumption in Appendix A we can derive the welfare change due to policy reforms with the following mutual exchanges of policy instruments.

First, we keep the parental leave rate, $\gamma$, constant and consider a budget neutral substitution of child benefits, $\alpha$, and subsidies for external child care, $\beta$. Taking account of the results of the comparative statics, an increase in $\beta$ accompanied by a reduction in $\alpha$ keeps the government's budget constant if $d \alpha=-\pi \bar{g} d \beta$ :

$$
\begin{aligned}
\left.\frac{d V}{d \beta}\right|_{d \alpha=-\pi \bar{g} d \beta}= & \lambda \pi\left(g_{i}-\bar{g}\right) n_{i} \\
& +\lambda \pi \bar{n} \frac{\mu}{\bar{D}}\left\{[ ( t \overline { w } + \gamma \overline { \widehat { w } } ) u _ { q _ { z } q _ { z } } \overline { P _ { q _ { h } } P _ { q _ { g } } } - \beta \pi ( u _ { q _ { z } q _ { z } \overline { P _ { q _ { h } } ^ { 2 } } } + u _ { q _ { h } q _ { h } } \overline { P _ { q _ { z } } ^ { 2 } } ) ] \left(\bar{n} u_{c c} u_{n n}\right.\right. \\
& \left.+2 u_{n} u_{c c}-\frac{u_{c}^{2}}{\bar{n}}\right)+u_{q_{h} q_{h}} u_{q_{z} q_{z}} \overline{P_{q_{g}}}[\alpha+\beta \pi \bar{g}+\bar{h}(\gamma \overline{\widehat{w}}+t \bar{w})]\left(u_{c c} \overline{P_{n}}-\frac{u_{c}}{\bar{n}}\right) \\
& \left.-\beta \pi \bar{n} u_{q_{h} q_{h}} u_{q_{z} q_{z}}\left(u_{c c} \overline{P_{n}^{2}}+u_{n n}\right)\right\}
\end{aligned}
$$

where the determinant of the bordered Hessian matrix for the average consumer is negative: $\bar{D}<0^{2}$.

This policy exchange can lead to changes of welfare in both directions depending on the initial consumption of external child care, the number of children, and the size of the subsidy $\beta$ which already exists. For example families with average or below average demand for external child care will be affected negatively by a further increase of the subsidy if the

\footnotetext{
${ }^{2}$ The determinant of the bordered Hessian matrix of an average individual is given by $\bar{D}=-\left(u_{q_{g} q_{g}} u_{q_{z} q_{z}} \overline{P_{q_{h}}^{2}}+u_{q_{h} q_{h}} u_{q_{z} q_{z}} \overline{P_{q_{g}}^{2}}+u_{q_{h} q_{h}} u_{q_{g} q_{g}} \overline{P_{q_{z}}^{2}}\right)$$$
\left(u_{c c} u_{n n}+\frac{2 u_{c c} u_{n}}{\bar{n}}-\frac{u_{c}^{2}}{\overline{n^{2}}}\right)-u_{q_{h} q_{h}} u_{q_{g} q_{g}} u_{q_{z} q_{z}}\left(u_{c c} \overline{P_{n}^{2}}+u_{n n}\right)<0
$$ 
subsidy is already quite high. For those families the subsidy is not important as a transfer and as net contributors to the subsidy scheme their utility falls by a further increase of $\beta$.

A definite improvement of welfare can be derived when looking at an introduction of a subsidy for external child care (the case of $\beta=0$ ). If child benefits are already used, we find that complementing this instrument by subsidies increases the utility of all families consuming at least the average time of external child care, that is $g_{i} \geq \bar{g}$, as the second term is positive:

$$
\begin{aligned}
\left.\frac{d V}{d \beta}\right|_{d \alpha=-\pi \bar{g} d \beta, \beta=} & \\
& =\lambda \pi\left(g_{i}-\bar{g}\right) n_{i} \\
& +\lambda \pi \bar{n} u_{q_{z} q_{z}} \overline{P_{q_{g}}} \frac{\mu}{\bar{D}}\left\{\overline{P_{q_{h}}}(t \bar{w}+\gamma \overline{\widehat{w}})\left(\bar{n} u_{c c} u_{n n}+2 u_{n} u_{c c}-\frac{u_{c}^{2}}{\bar{n}}\right)\right. \\
& \left.+u_{q_{h} q_{h}}[\alpha+\bar{h}(\gamma \overline{\widehat{w}}+t \bar{w})]\left(u_{c c} \overline{P_{n}}-\frac{u_{c}}{\bar{n}}\right)\right\}
\end{aligned}
$$

The budget-neutral policy exchange of child benefits to a subsidy for external child care is therefore positive for all families consuming $g_{i} \geq \bar{g}$ starting at the introduction up to a certain initial provision level of the subsidy. The larger the initial provision level of the subsidy for external child care the smaller becomes the group of families who benefit from the policies exchange.

Proposition 6: A budget-neutral increase of a subsidy on external child care accompanied by a decrease in child benefits leads to higher parental welfare in the case of identical families and for heterogeneous families consuming at least average external child care $\left(g_{i} \geq \bar{g}\right)$ if the subsidy is being introduced and up to a certain initial provision level.

Keeping $\beta$ constant, a budget neutral substitution of child benefits and the rate of parental leave payments requires $d \alpha=-\overline{\widehat{w}} \bar{h} d \gamma$. Using our results of the comparative statics, an increase of $\gamma$ accompanied by a reduction of $\alpha$ has the following effect on the families' welfare: 


$$
\begin{aligned}
\left.\frac{d V}{d \gamma}\right|_{d \alpha=-\bar{w} \bar{h} d \gamma}= & \lambda\left(\widehat{w}_{i} h_{i}-\overline{\widehat{w}} \bar{h}\right) n_{i} \\
& +\lambda \overline{\widehat{w}} \bar{n} \frac{\mu}{\bar{D}}\left\{\left[\beta \pi u_{q_{z} q_{z}} \overline{P_{q_{h}} \bar{P}_{q_{g}}}\right.\right. \\
& \left.-(t \bar{w}+\gamma \overline{\widehat{w}})\left(u_{q_{g} q_{g}} \overline{P_{q_{z}}^{2}}+u_{q_{z} q_{z}} \overline{P_{g}^{2}}\right)\right]\left(\bar{n} u_{c c} u_{n n}+2 u_{n} u_{c c}-\frac{u_{c}^{2}}{\bar{n}}\right) \\
& +[\alpha+\beta \pi \bar{g}+\bar{h}(t \bar{w}+\gamma \overline{\widehat{w}})] u_{q_{g} q_{g}} u_{q_{z} q_{z}} \overline{P_{q_{h}}}\left(u_{c c} \overline{P_{n}}-\frac{u_{c}}{\bar{n}}\right) \\
& \left.-(t \bar{w}+\gamma \overline{\widehat{w}}) \bar{n} u_{q_{g} q_{g}} u_{q_{z} q_{z}}\left(u_{c c} \overline{P_{n}^{2}}+u_{n n}\right)\right\}
\end{aligned}
$$

As before the welfare effect in general can go in either direction. The effect of higher parental leave payments is likely to be positive for families with secondary earners whose opportunity costs for parental time are above average, that is $\widehat{w}_{i} h_{i}>\overline{\widehat{w}} \bar{h}$, and if the initial parental leave payment rate $\gamma$ is small. As before, we observe redistribution with respect to the income weighted parental child care time but in case of the parents' welfare additionally with respect to the number of children due to the redistribution of income for family policies. The size of this effect therefore depends on the secondary earner's net wage rate, her parental child care time, and the family's number of children.

When looking at the case of $\gamma=0$, we find that the size of the welfare effect depends on the size of the average tax payments $t \bar{w}$ of secondary earners

$$
\begin{aligned}
\left.\frac{d V}{d \gamma}\right|_{d \alpha=-\bar{w} \bar{h} d \gamma, \gamma}= & \\
& =\lambda\left(\widehat{w}_{i} h_{i}-\overline{\widehat{w}} \bar{h}\right) n_{i} \\
& +\lambda \bar{w} \bar{n} \frac{\mu}{\bar{D}}\left\{[ \beta \pi u _ { q _ { z } q _ { z } } \overline { P _ { q _ { h } } P _ { q _ { g } } } - t \overline { w } ( u _ { q _ { g } q _ { g } } \overline { P _ { q _ { z } } ^ { 2 } } + u _ { q _ { z } q _ { z } } \overline { P _ { q _ { g } } ^ { 2 } } ) ] \left(\bar{n} u_{c c} u_{n n}\right.\right. \\
& \left.+2 u_{n} u_{c c}-\frac{u_{c}^{2}}{\bar{n}}\right)+(\alpha+\beta \pi \bar{g}+t \bar{w} \bar{h}) u_{q_{g} q_{g}} u_{q_{z} q_{z}} \overline{P_{q_{h}}}\left(u_{c c} \overline{P_{n}}-\frac{u_{c}}{\bar{n}}\right) \\
& \left.-t \bar{w} \bar{n} u_{q_{g} q_{g}} u_{q_{z} q_{z}}\left(u_{c c} \overline{P_{n}^{2}}+u_{n n}\right)\right\}
\end{aligned}
$$

If the average secondary earners' tax payments $t \bar{w}$ are small enough, the welfare effect is positive for secondary earners whose opportunity costs for parental time are at least at the average, that is $\widehat{w}_{i} h_{i} \geq \overline{\widehat{w}} \bar{h}$. For those net recipients of parental leave payments the positive effect of introducing the transfers is higher than the burden of tax financing the scheme.

For $\gamma=1$ we find that the size of the welfare effect depends only on the average wage rate of the secondary earners: 


$$
\begin{aligned}
\left.\frac{d V}{d \gamma}\right|_{d \alpha=-\bar{w} \bar{h} d \gamma, \gamma=} & \\
& =\lambda\left(\widehat{w}_{i} h_{i}-\overline{\widehat{w}} \bar{h}\right) n_{i} \\
& +\lambda \overline{\widehat{w}} \bar{n} \frac{\mu}{\bar{D}}\left\{[ \beta \pi u _ { q _ { z } q _ { z } } \overline { P _ { q _ { h } } P _ { q _ { g } } } - \overline { w } ( u _ { q _ { g } q _ { g } } \overline { P _ { q _ { z } } ^ { 2 } } + u _ { q _ { z } q _ { z } } \overline { P _ { g } ^ { 2 } } ) ] \left(\bar{n} u_{c c} u_{n n}\right.\right. \\
& \left.+2 u_{n} u_{c c}-\frac{u_{c}^{2}}{\bar{n}}\right)+(\alpha+\beta \pi \bar{g}+\bar{w} \bar{h}) u_{q_{g} q_{g}} u_{q_{z} q_{z}} \overline{P_{q_{h}}}\left(u_{c c} \overline{P_{n}}-\frac{u_{c}}{\bar{n}}\right) \\
& \left.-\bar{w} \bar{n} u_{q_{g} q_{g}} u_{q_{z} q_{z}}\left(u_{c c} \overline{P_{n}^{2}}+u_{n n}\right)\right\}
\end{aligned}
$$

The welfare effect is now positive for secondary earners whose opportunity costs for parental time are above average, that is $\widehat{w}_{i} h_{i}>\bar{w} \bar{h}$, if the average wage rate is relatively small.

If $\gamma$ equals unity all of the foregone net wage income due to the parental child care at home is fully compensated by the leave payments. Hence, the implicit tax on wage income is maximum at this rate $\gamma$. The net wage income of the household including leave payments according to (3) is then given by $(1-t)(Y+w)$. This shows us that with increasing provision level of parental leave payments, the distortive part of taxes on wage income becomes less important and what remains is a lump-sum tax on the full income. The higher the full income the less likely the welfare effect is positive.

As described before, families with $\widehat{w}_{i} h_{i}>\overline{\widehat{w}} \bar{h}$ are net recipients of the parental leave payments. Nevertheless families with $\widehat{w}_{i}>\widehat{\widehat{w}}$ finance the policy instruments and, therefore, only benefit from a budget-neutral increase in parental leave payments if the average secondary earners' income is low and there is thus little redistribution with respect to parental leave payments.

Proposition 7: A budget-neutral increase of parental leave payments accompanied by a decrease in child benefits leads to a higher parental welfare for families with $\widehat{w}_{i} h_{i} \geq \overline{\widehat{w}} \bar{h}$ from the introduction up to a certain initial provision level of leave payments if the average tax payments of secondary earners are sufficiently small.

Keeping $\alpha$ constant, an increase of a subsidy for child care accompanied by a decrease of the rate of parental leave payments is budget neutral if $d \gamma=-\frac{\pi \bar{g}}{\overline{\bar{w}} \bar{h}} d \beta$. This equals a comparison of the two aforementioned welfare effects of the budget-neutral exchanges of $\alpha$ and $\beta$ as well as $\alpha$ and $\gamma$. Substituting $\gamma$ for $\beta$ has the following effect on the parents' welfare: 


$$
\begin{aligned}
& \left.\frac{d V}{d \beta}\right|_{d \gamma=-\frac{\pi \bar{g}}{\bar{w} \bar{h}} d \beta}=\lambda \pi n_{i}\left(g_{i}-\frac{\widehat{w}_{i} h_{i}}{\widehat{\widehat{w}} \bar{h}} \bar{g}\right) \\
& +\lambda \pi \bar{n} \frac{\mu}{\bar{D}}\left\{\left[\beta \pi\left(u_{q_{z} q_{z}} \overline{P_{q_{h}}^{2}}+u_{q_{h} q_{h}} \overline{P_{q_{z}}^{2}}+\frac{\bar{g}}{\bar{h}} u_{q_{z} q_{z}} \overline{P_{q_{h}} P_{q_{g}}}\right)\right.\right. \\
& \left.-(t \bar{w}+\gamma \overline{\widehat{w}})\left(\frac{\bar{g}}{\bar{h}} u_{q_{z} q_{z}} \overline{P_{q_{g}}^{2}}+\frac{\bar{g}}{\bar{h}} u_{q_{g} q_{g}} \overline{P_{q_{z}}}+u_{q_{z} q_{z}} \overline{P_{q_{h}} P_{q_{g}}}\right)\right]\left(\bar{n} u_{c c} u_{n n}\right. \\
& \left.+2 u_{n} u_{c c}-\frac{u_{c}^{2}}{\bar{n}}\right) \\
& -u_{q_{z} q_{z}}\left(u_{q_{h} q_{h}} \overline{P_{g}}-\frac{\bar{g}}{\bar{h}} u_{q_{g} q_{g}} \overline{P_{q_{h}}}\right)[\alpha+\beta \pi \bar{g}+\bar{h}(t \bar{w}+\gamma \overline{\widehat{w}})]\left(u_{c c} \overline{P_{n}}-\frac{u_{c}}{\bar{n}}\right) \\
& \left.+\bar{n} u_{q_{z} q_{z}}\left[\beta \pi u_{q_{h} q_{h}}-\frac{\bar{g}}{\bar{h}}(t \bar{w}+\gamma \overline{\widehat{w}}) u_{q_{g} q_{g}}\right]\left(u_{c c} \overline{P_{n}^{2}}+u_{n n}\right)\right\}
\end{aligned}
$$

The size of the welfare effect of the budget neutral increase of the subsidy for child care in (35) depends to a large extent on family $i$ 's ratio of consumption of $g_{i}$ to $h_{i}$ as well as on the average ratio of consumption of $\bar{g}$ to $\bar{h}$. In general, the welfare effect can go in either direction. We can say more in two special cases.

Introducing the subsidy for external child care $(\beta=0)$ :

$$
\begin{aligned}
\left.\frac{d V}{d \beta}\right|_{d \gamma=-\frac{\pi \bar{g}}{\overline{\bar{w}}} d \beta, \beta}= & \\
& =\lambda \pi n_{i}\left(g_{i}-\frac{\widehat{w}_{i} h_{i}}{\overline{\widehat{w}} \bar{h}} \bar{g}\right) \\
& -\lambda \pi \bar{n} \frac{\mu}{\bar{D}}\left\{[ ( t \overline { w } + \gamma \overline { \widehat { w } } ) ( \frac { \overline { g } } { \overline { h } } u _ { q _ { z } q _ { z } } \overline { P _ { g } ^ { 2 } } + \frac { \overline { g } } { \overline { h } } u _ { q _ { g } q _ { g } } \overline { P _ { q _ { z } } } + u _ { q _ { z } q _ { z } } \overline { P _ { q _ { h } } P _ { q _ { g } } } ) ] \left(\bar{n} u_{c c} u_{n n}\right.\right. \\
& \left.+2 u_{n} u_{c c}-\frac{u_{c}^{2}}{\bar{n}}\right) \\
& +u_{q_{z} q_{z}}\left(u_{q_{h} q_{h}} \overline{P_{q_{g}}}-\frac{\bar{g}}{\bar{h}} u_{q_{g} q_{g}} \overline{P_{q_{h}}}\right)[\alpha+\bar{h}(t \bar{w}+\gamma \overline{\widehat{w}})]\left(u_{c c} \overline{P_{n}}-\frac{u_{c}}{\bar{n}}\right) \\
& \left.+\bar{n} \frac{\bar{g}}{\bar{h}}(t \bar{w}+\gamma \overline{\widehat{w}}) u_{q_{g} q_{g}} u_{q_{z} q_{z}}\left(u_{c c} \overline{P_{n}^{2}}+u_{n n}\right)\right\}
\end{aligned}
$$

we find that the welfare effect is negative for all secondary earners whose ratio of own to average external child care is not larger than their ratio of own to average opportunity costs of staying at home, that is $\frac{g_{i}}{\bar{g}} \leq \frac{\widehat{w}_{i} h_{i}}{\bar{w} \bar{h}}$, if the average negative price elasticity of external child care is smaller than the average negative elasticity of parental child care with respect to the opportunity costs, that is $u_{q_{h} q_{h}} \overline{P_{q_{g}}}<\frac{\bar{g}}{\bar{h}} u_{q_{g} q_{g}} \overline{P_{q_{h}}} \quad$. This group of secondary earners benefits most from high parental leave payments. Therefore, a budget-neutral increase of the subsidy

\footnotetext{
${ }^{3}$ This condition is equivalent to the requirement that the average elasticity of marginal utility w.r.t. $h$ is smaller than w.r.t. $g$, that is $\bar{\varepsilon}_{g}<\bar{\varepsilon}_{h}$.
} 
for external child care creates a welfare loss for those families as long as the provision level is low. For an increasing provision level, the welfare effect is ambiguous for families with $\frac{g_{i}}{\bar{g}} \leq \frac{\widehat{w}_{i} h_{i}}{\overline{\widehat{w}} \bar{h}}$ and likely to be positive for families with $\frac{g_{i}}{\bar{g}}>\frac{\widehat{w}_{i} h_{i}}{\bar{w} \bar{h}}$.

For very high levels of parental leave payments $(\gamma=1)$ and with $\frac{g_{i}}{\bar{g}} \geq \frac{\widehat{w}_{i} h_{i}}{\widehat{w} \bar{h}}$ at the starting point of the policy change we derive the following welfare result:

$$
\begin{aligned}
\left.\frac{d V}{d \beta}\right|_{d \gamma=-\frac{\pi \bar{g}}{\bar{w} \bar{h}} d \beta, \gamma=} & \\
= & \lambda \pi n_{i}\left(g_{i}-\frac{\widehat{w}_{i} h_{i}}{\overline{\widehat{w}} \bar{h}} \bar{g}\right) \\
& +\lambda \pi \bar{n} \frac{\mu}{\bar{D}}\left\{\left[\beta \pi\left(u_{q_{z} q_{z}} \overline{P_{q_{h}}^{2}}+u_{q_{h} q_{h}} \overline{P_{q_{z}}^{2}}+\frac{\bar{g}}{\bar{h}} u_{q_{z} q_{z}} \overline{P_{q_{h}} P_{q_{g}}}\right)\right.\right. \\
& \left.-\bar{w}\left(\frac{\bar{g}}{\bar{h}} u_{q_{z} q_{z}} \overline{P_{q_{g}}^{2}}+\frac{\bar{g}}{\bar{h}} u_{q_{g} q_{g}} \overline{P_{q_{z}}}+u_{q_{z} q_{z}} \overline{P_{q_{h}} P_{q_{g}}}\right)\right]\left(\bar{n} u_{c c} u_{n n}+2 u_{n} u_{c c}-\frac{u_{c}^{2}}{\bar{n}}\right) \\
& -u_{q_{z} q_{z}}\left(u_{q_{h} q_{h}} \overline{P_{q_{g}}}-\frac{\bar{g}}{\bar{h}} u_{q_{g} q_{g}} \overline{P_{q_{h}}}\right)[\alpha+\beta \pi \bar{g}+\bar{h} \bar{w}]\left(u_{c c} \overline{P_{n}}-\frac{u_{c}}{\bar{n}}\right) \\
& \left.+\bar{n} u_{q_{z} q_{z}}\left[\beta \pi u_{q_{h} q_{h}}-\frac{\bar{g}}{\bar{h}} \bar{w} u_{q_{g} q_{g}}\right]\left(u_{c c} \overline{P_{n}^{2}}+u_{n n}\right)\right\}
\end{aligned}
$$

If the average gross wage $\bar{w}$ is small so that the income effect of parental leave payments is low and if the rate of leave payments is very high $(\gamma \rightarrow 1)$ the substitution of the high parental leave payments by subsidies for external child care improves the welfare if $\bar{\varepsilon}_{g}<\bar{\varepsilon}_{h}$ in the society holds. For those families who benefit relatively more from the subsidies for external child care than from the parental leave payments, i.e. $\frac{g_{i}}{\bar{g}} \geq \frac{\widehat{w}_{i} h_{i}}{\bar{w} \bar{h}}$, the replacement rate of leave payments is thus too high so that an exchange towards more subsidies is welfare improving.

Proposition 8: A budget-neutral increase of a subsidy on external child care accompanied by a decrease in parental leave payments leads to a decrease in parental welfare for families with $\frac{g_{i}}{\bar{g}} \leq \frac{\widehat{w}_{i} h_{i}}{\overline{\widehat{w}} \bar{h}}$ if the society responds more elastic to price changes of external child care than to changes of opportunity costs of staying at home, i.e. $\bar{\varepsilon}_{g}<\bar{\varepsilon}_{h}$, if the provision level of the subsidy is low. If, on the other hand, the rate of parental leave payments is very high and the average gross wage income is low the same policy exchange can be welfare improving for families with $\frac{g_{i}}{\bar{g}} \geq \frac{\widehat{w}_{i} h_{i}}{\widehat{\widehat{w}} \bar{h}}$ if $\bar{\varepsilon}_{g}<\bar{\varepsilon}_{h}$ holds. 


\section{Conclusion}

Our results suggest that both a subsidy for external child care and parental leave payments have ambiguous effects on fertility. This result is in line with empirical findings that show mixed evidence about the success of the two policy parameters in fostering fertility (see Thévenon and Gauthier, 2011, and Luci-Greulich and Thévenon, 2013 for an overview). Luci-Greulich and Thévenon (2013) argue that the ambiguity of the impact of parental leave payments on fertility is due to the policy design: On the one hand, the policy instrument supports household income and labor market participation around the time of childbirth, which has a positive effect on fertility. However, as entitlements are often conditional on employment, they encourage men and women to postpone childbirth (which has a negative effect on overall fertility) until they have established themselves in the labor market. This hypothesis is confirmed by Adsera (2004) who uses a panel of 23 OECD nations to study how different labor market arrangements shaped the correlation between fertility and female labor participation rates in the countries respectively. Her results suggest that labor market insecurity, as measured by unemployment, has a significantly negative impact on fertility. She thus finds that an increase in paid leave duration has a positive impact on fertility rates. This result is in line with our finding that the impact of an increase of leave payments on fertility depends on the secondary earner's wage rate and on the elasticity of demand for parental child care time. Our model, however, sheds a rather unfavorable light on parental leave payments as we model the instrument within a static framework. We highlight that parental leave payments work like an implicit tax on continued work and therefore have a negative impact on the secondary earner's labor supply. We thus ignore the presumably positive long-term effects of the policy instrument on the secondary earner's labor supply via the channel of job market security. These dynamic aspects of leave payments are left for future research.

Regarding the reconciliation of family and work our results show that in our framework a policy reform that sets incentives for more children and a higher demand for external child care and, at the same time, stimulates more labor supply of parents is given by an increase of child benefits compensated by a budget-neutral reduction of parental leave payments. Another finding is that a policy change that shifts transfers from leave payments to subsidies for external child care increases the demand for external child care and the employment of secondary earners. This budget-neutral policy exchange can also set positive incentives for having children if the demand for external child care is not too elastic. These findings have been confirmed in the empirical literature. Luci-Greulich and Thévenon (2013) empirically 
test the impact of the three family policy instruments on fertility, using macro panel data from 18 OECD countries that spans the years 1982-2007. Their results show that paid leave, childcare services and financial transfers have a positive influence on average, suggesting that the combination of these forms of support has a positive effect on the demand for children for working parents. However, their findings also suggest that the policy instruments do not all have the same weight: cash benefits covering childhood after the year of childbirth and the provision of childcare services for children under age three have a larger potential influence on fertility than leave entitlements and benefits granted around childbirth. Luci-Greulich and Thévenon (2013) show that a mix of in-cash and in-kind support has a positive influence on fertility and that the development of child care services has a more significant impact on fertility trends at the aggregate level than policies extending leave entitlements. Fehr and Ujhelyiova (2013) also find that in principle it is possible to increase birth rates and female employment rates simultaneously if the government invests in child care facilities for children of all ages.

Our results with respect to welfare show that if child benefits are part of the family policy in an economy it is welfare improving to complement this by introducing subsidies to external child care in exchange for lower child benefits up to a certain provision level. This holds true in the case of identical families as well as for families with above average demand for external child care - the net beneficiaries. We find that it may also increase welfare to substitute very high levels of parental leave payments by subsidies for external child care. If the average gross wage $\bar{w}$ is small so that the income effect of parental leave payments is low this policy change is beneficial for families who respond more elastic to changes in opportunity costs of parental child care than to price changes of external child care. For those families who benefit relatively more from the subsidies for external child care than from the parental leave payments the replacement rate of leave payments is too high so that an exchange towards more subsidies is welfare improving. 


\section{References}

Adsera, Alícia (2004): “Changing fertility rates in developed countries: The impact of labor market institutions”, Journal of Population Economics, 17 (1), 17-43.

Apps, Patricia and Ray Rees (2004): "Fertility, Taxation and Family Policy”, Scandinavian Journal of Economics, 106 (4), 745-763.

Becker, Gary S. (1960): “An Economic Analysis of Fertility”, in Demographic and Economic Change in Developed Countries, a conference of the Universities-National Bureau Committee for Economic Research. Princeton University Press, for the National Bureau of Economic Research: Princeton, N.J..

Becker, Gary S. and Gregg H. Lewis (1973): "On the Interaction between the Quantity and Quality of Children”, Journal of Political Economy , 81 (2), 279-288.

Becker, Gary S. (1981): “A Treatise on the Family”, Harvard University Press: Cambridge, Massachusetts.

Bergemann Annette and Regina T. Riphahn (2011): "Female labour supply and parental leave benefits - the causal effect of paying higher transfers for a shorter period of time", Applied Economics Letters, 18, 17-20.

Cigno, Alessandro (1986): "Fertility and the Tax-Benefit System: A Reconsideration of the Theory of Family Taxation”, The Economic Journal, 96, 1035-1051.

Cigno, Alessandro (1991): “Economics of the Family”, Clarendon Press: Oxford.

Cigno, Alessandro, Luca Casolaro, and Furio C. Rosati (2003): “The Impact of Social Security on Saving and Fertility in Germany”, Finanzarchiv, 59 (2), 189-211.

Cigno, Alessandro and Annalisa Luporini (2011): “Optimal Family Policy in the Presence of Moral Hazard when the Quantity and Quality of Children are Stochastic”, CESifo Economic Studies 57, 349-364.

Ermisch, John F. (1989): "Purchased Child Care, Optimal Family Size and Mother's Employment: Theory and Econometric Analysis”, Journal of Population Economics, 2, 79-102.

Fehr, Hans and Daniela Ujhelyiova (2013): Fertility, Female Labor Supply, and Family Policy”, German Economic Review, 14 (2), 138-165.

Gauthier, Anne H. and Jan Hatzius (1997): "Family benefits and fertility: An econometric analysis”, Population Studies, 51, 295-306.

Han, Wen-Jui, Christopher Ruhm, and Jane Waldfogel (2009): "Parental Leave Policies and Parents’ Employment and Leave-Taking“, Journal of Policy Analysis and Management, 28 (1), 29-54. 
Hank, Karsten, Michaela Kreyenfeld, and C. Katharina Spiess (2004): "Kinderbetreuung und Fertilität in Deutschland“, Zeitschrift für Soziologie, 33 (3), 228-244.

Haan, Peter and Katharina Wrohlich (2009): “Can Child Care Policy Encourage Employment and Fertility? Evidence from a Structural Model", IZA Discussion Paper No. 4503.

Lalive, Rafael and Josef Zweimüller (2009): "Does Parental Leave Affect Fertility and Return-To-Work? Evidence from two Natural Experiments”, Quarterly Journal of Economics, 124, 13363-1402.

Laroque, Guy and Bernard Salanié (2005): “Does Fertility Respond to Financial Incentives?”, CEPR Discussion Papers Nr. 5007.

Luci-Greulich, Angela and Olivier Thévenon (2013): “The Impact of Family Policies on Fertility Trends in Developed Countries”, European Journal of Population, 29, 387-416.

Meier, Volker and Matthias Wrede (2008): "Reducing the Excess Burden of Subsidizing the Stork: Joint Taxation, Individual Taxation, and Family Tax Splitting“, CESifo Working Paper No. 2470.

Milligan, Kevin (2005): "Subsidizing the Stork: New Evidence on Tax Incentives and Fertility”, The Review of Economics and Statistics, 87 (3), 539-555.

Pronzato, Chiara D. (2009): "Return to Work after Childbirth: does Parental Leave Matter in Europe?", Review of Economics of the Household, 4, 341-360.

Sinn, Hans-Werner (2005): “Europe’s Demographic Deficit. A Plea for a Child Pension System, De Economist, 153, 1-45.

Thévenon, Olivier and Anne H. Gauthier (2011): "Family policies in developed countries: A fertility booster with side-effects”, Community Work and Family, 14 (2), 197-216.

Willis, Robert J. (1973): “A New Approach to the Economic Theory of Fertility Behavior”, Journal of Political Economy, 81 (2), 14-64. 


\section{Appendix}

\section{A: Derivation of the comparative statics results}

Total differentiation of the first-order conditions of individual utility maximization (5) - (8) yields:

$$
\begin{gathered}
\left(\begin{array}{cccccc}
u_{c c} & 0 & 0 & 0 & 0 & -1 \\
0 & u_{n n} & -\lambda \widehat{w}_{i}(1-\gamma) & -\lambda(1-\beta) \pi & -\lambda B & -P_{n, i} \\
0 & -\lambda \widehat{w}_{i}(1-\gamma) & u_{q_{h} q_{h}} & 0 & 0 & -P_{q_{h}, i} \\
0 & -\lambda(1-\beta) \pi & 0 & u_{q_{g} q_{g}} & 0 & -P_{q_{g}, i} \\
0 & -\lambda B & 0 & 0 & u_{q_{z} q_{z}} & -P_{q_{z}, i} \\
-1 & -P_{n, i} & -P_{q_{h}, i} & -P_{q_{g}, i} & -P_{q_{z}, i} & 0
\end{array}\right)\left(\begin{array}{c}
d c_{i} \\
d n_{i} \\
d h_{i} \\
d g_{i} \\
d z_{i} \\
d \lambda
\end{array}\right) \\
=\left(\begin{array}{ccc}
0 & 0 & 0 \\
-\lambda & -\lambda \pi g_{i} & -\lambda \widehat{w}_{i} h_{i} \\
0 & 0 & -\lambda \widehat{w}_{i} n_{i} \\
0 & -\lambda \pi n_{i} & 0 \\
0 & 0 & 0 \\
-n_{i} & -\pi g_{i} n_{i} & -\widehat{w}_{i} h_{i} n_{i}
\end{array}\right)\left(\begin{array}{l}
d \alpha \\
d \beta \\
d \gamma
\end{array}\right)
\end{gathered}
$$

where the determinant of the bordered Hessian matrix on the left-hand side is denoted by $D_{i}$. The Cramer rule yields the following derivatives:

$$
\begin{aligned}
& d c_{i}=\left(\lambda \frac{D_{21}}{D_{i}}+\right.\left.n_{i} \frac{D_{61}}{D_{i}}\right) d \alpha+\left(\lambda \pi g_{i} \frac{D_{21}}{D_{i}}+\lambda \pi n_{i} \frac{D_{41}}{D_{i}}+\pi g_{i} n_{i} \frac{D_{61}}{D_{i}}\right) d \beta \\
&+\left(\lambda \widehat{w}_{i} h_{i} \frac{D_{21}}{D_{i}}-\lambda \widehat{w}_{i} n_{i} \frac{D_{31}}{D_{i}}+\widehat{w}_{i} h_{i} n_{i} \frac{D_{61}}{D_{i}}\right) d \gamma \\
& d n_{i}=\left(-\lambda \frac{D_{22}}{D_{i}}-n_{i} \frac{D_{62}}{D_{i}}\right) d \alpha+\left(-\lambda \pi g_{i} \frac{D_{22}}{D_{i}}-\lambda \pi n_{i} \frac{D_{42}}{D_{i}}-\pi g_{i} n_{i} \frac{D_{62}}{D_{i}}\right) d \beta \\
&+\left(-\lambda \widehat{w}_{i} h_{i} \frac{D_{22}}{D_{i}}+\lambda \widehat{w}_{i} n_{i} \frac{D_{32}}{D_{i}}-\widehat{w}_{i} h_{i} n_{i} \frac{D_{62}}{D_{i}}\right) d \gamma \\
& d h_{i}=\left(\lambda \frac{D_{23}}{D_{i}}+n_{i} \frac{D_{63}}{D_{i}}\right) d \alpha+\left(\lambda \pi g_{i} \frac{D_{23}}{D_{i}}+\lambda \pi n_{i} \frac{D_{43}}{D_{i}}+\pi g_{i} n_{i} \frac{D_{63}}{D_{i}}\right) d \beta \\
&+\left(\lambda \widehat{w}_{i} h_{i} \frac{D_{23}}{D_{i}}-\lambda \widehat{w}_{i} n_{i} \frac{D_{33}}{D_{i}}+\widehat{w}_{i} h_{i} n_{i} \frac{D_{63}}{D_{i}}\right) d \gamma
\end{aligned}
$$




$$
\begin{gathered}
d g_{i}=\left(-\lambda \frac{D_{24}}{D_{i}}-n_{i} \frac{D_{64}}{D_{i}}\right) d \alpha+\left(-\lambda \pi g_{i} \frac{D_{24}}{D_{i}}-\lambda \pi n_{i} \frac{D_{44}}{D_{i}}-\pi g_{i} n_{i} \frac{D_{64}}{D_{i}}\right) d \beta \\
+\left(-\lambda \widehat{w}_{i} h_{i} \frac{D_{24}}{D_{i}}+\lambda \widehat{w}_{i} n_{i} \frac{D_{34}}{D_{i}}-\widehat{w}_{i} h_{i} n_{i} \frac{D_{64}}{D_{i}}\right) d \gamma \\
d z_{i}=\left(\lambda \frac{D_{25}}{D_{i}}+n_{i} \frac{D_{65}}{D_{i}}\right) d \alpha+\left(\lambda \pi g_{i} \frac{D_{25}}{D_{i}}+\lambda \pi n_{i} \frac{D_{45}}{D_{i}}+\pi g_{i} n_{i} \frac{D_{54}}{D_{i}}\right) d \beta \\
+\left(\lambda \widehat{w}_{i} h_{i} \frac{D_{25}}{D_{i}}-\lambda \widehat{w}_{i} n_{i} \frac{D_{35}}{D_{i}}+\widehat{w}_{i} h_{i} n_{i} \frac{D_{565}}{D_{i}}\right) d \gamma
\end{gathered}
$$

where the minors of the Hessian matrix are given by

$$
\begin{aligned}
& D_{i}=-\left(u_{q_{g} q_{g}} u_{q_{z} q_{z}} P_{q_{h}, i}^{2}+u_{q_{h} q_{h}} u_{q_{z} q_{z}} P_{q_{g}, i}^{2}+u_{q_{h} q_{h}} u_{q_{g} q_{g}} P_{q_{z}, i}^{2}\right)\left(u_{c c} u_{n n}+\frac{2 u_{c c} u_{n}}{n_{i}}-\frac{u_{c}^{2}}{n_{i}^{2}}\right) \\
& -u_{q_{h} q_{h}} u_{q_{g} q_{g}} u_{q_{z} q_{z}}\left(u_{c c} P_{n, i}^{2}+u_{n n}\right)<0 \\
& D_{21}=-u_{q_{h} q_{h}} u_{q_{g} q_{g}} u_{q_{z} q_{z}} P_{n, i}-\frac{u_{c}}{n_{i}}\left(u_{q_{g} q_{g}} u_{q_{z} q_{z}} P_{q_{h}, i}^{2}+u_{q_{h} q_{h}} u_{q_{z} q_{z}} P_{q_{g}, i}^{2}+u_{q_{h} q_{h}} u_{q_{g} q_{g}} P_{q_{z}, i}^{2}\right)<0 \\
& D_{22}=-u_{c c}\left(u_{q_{g} q_{g}} u_{q_{z} q_{z}} P_{q_{h}, i}^{2}+u_{q_{h} q_{h}} u_{q_{z} q_{z}} P_{q_{g}, i}^{2}+u_{q_{h} q_{h}} u_{q_{g} q_{g}} P_{q_{z}, i}^{2}\right)-u_{q_{h} q_{h}} u_{q_{g} q_{g}} u_{q_{z} q_{z}}>0 \\
& D_{23}=D_{32}=-u_{q_{g} q_{g}} u_{q_{z} q_{z}} P_{q_{h}, i}\left(u_{c c} P_{n, i}-\frac{u_{c}}{n_{i}}\right)>0 \\
& D_{24}=D_{42}=u_{q_{h} q_{h}} u_{q_{z} q_{z}} P_{q_{g}, i}\left(u_{c c} P_{n, i}-\frac{u_{c}}{n_{i}}\right)<0 \\
& D_{25}=-u_{q_{h} q_{h}} u_{q_{g} q_{g}} P_{q_{\mathrm{z}}, i}\left(u_{c c} P_{n, i}-\frac{u_{c}}{n_{i}}\right)>0 \\
& D_{31}=u_{q_{g} q_{g}} u_{q_{z} q_{z}} P_{q_{h}, i}\left(u_{n n}+\frac{u_{n}}{n_{i}}\right)<0 \\
& D_{33}=-\left(u_{q_{g} q_{g}} P_{q_{z}, i}^{2}+u_{q_{z} q_{z}} P_{q_{g}, i}^{2}\right)\left(u_{c c} u_{n n}+\frac{2 u_{c c} u_{n}}{n_{i}}-\frac{u_{c}^{2}}{n_{i}^{2}}\right)-u_{q_{g} q_{g}} u_{q_{z} q_{z}}\left(u_{c c} P_{n, i}^{2}+u_{n n}\right)>0 \\
& D_{34}=D_{43}=-u_{q_{z} q_{z}} P_{q_{h}, i} P_{q_{g}, i}\left(u_{c c} u_{n n}+\frac{2 u_{c c} u_{n}}{n_{i}}-\frac{u_{c}^{2}}{n_{i}^{2}}\right)>0 \\
& D_{35}=u_{q_{g} q_{g}} P_{q_{h}, i} P_{q_{z}, i}\left(u_{c c} u_{n n}+\frac{2 u_{c c} u_{n}}{n_{i}}-\frac{u_{c}^{2}}{n_{i}^{2}}\right)<0 \\
& D_{41}=-u_{q_{h} q_{h}} u_{q_{z} q_{z}} P_{q_{g}, i}\left(u_{n n}+\frac{u_{n}}{n_{i}}\right)>0 \\
& D_{44}=-\left(u_{q_{z} q_{z}} P_{q_{h}, i}^{2}+u_{q_{h} q_{h}} P_{q_{z}}^{2}\right)\left(u_{c c} u_{n n}+\frac{2 u_{c c} u_{n}}{n_{i}}-\frac{u_{c}^{2}}{n_{i}^{2}}\right)-u_{q_{h} q_{h}} u_{q_{z} q_{z}}\left(u_{n n}+u_{c c} P_{n, i}{ }^{2}\right)>0
\end{aligned}
$$




$$
\begin{aligned}
& D_{45}=-u_{q_{h} q_{h}} P_{q_{g}, i} P_{q_{z}, i}\left(u_{c c} u_{n n}+\frac{2 u_{c c} u_{n}}{n_{i}}-\frac{u_{c}^{2}}{n_{i}^{2}}\right)>0 \\
& D_{61}=-u_{n n} u_{q_{h} q_{h}} u_{q_{g} q_{g}} u_{q_{z} q_{z}}+\frac{u_{c}^{2}}{n_{i}^{2}}\left(u_{q_{g} q_{g}} u_{q_{z} q_{z}} P_{q_{h}, i}^{2}+u_{q_{h} q_{h}} u_{q_{z} q_{z}} P_{q_{g}, i}^{2}+u_{q_{h} q_{h}} u_{q_{g} q_{g}} P_{q_{z}, i}^{2}\right)<0 \\
& D_{62}=u_{c c}\left[u_{q_{h} q_{h}} u_{q_{g} q_{g}} u_{q_{z} q_{z}} P_{n, i}+\frac{u_{c}}{n_{i}}\left(u_{q_{g} q_{g}} u_{q_{z} q_{z}} P_{q_{h}, i}^{2}+u_{q_{h} q_{h}} u_{q_{z} q_{z}} P_{q_{g}, i}^{2}+u_{q_{h} q_{h}} u_{q_{g} q_{g}} P_{q_{z}, i}^{2}\right)\right]>0 \\
& D_{63}=-u_{c c} u_{q_{g} q_{g}} u_{q_{z} q_{z}} P_{q_{h}, i}\left(u_{n n}+\frac{u_{n}}{n_{i}}\right)<0 \\
& D_{64}=u_{c c} u_{q_{h} q_{h}} u_{q_{z} q_{z}} P_{q_{g}, i}\left(u_{n n}+\frac{u_{n}}{n_{i}}\right)>0 \\
& D_{65}=-u_{c c} u_{q_{h} q_{h}} u_{q_{g} q_{g}} P_{q_{z}, i}\left(u_{n n}+\frac{u_{n}}{n_{i}}\right)<0
\end{aligned}
$$

and from the second-order conditions for a utility maximum: $\left(u_{c c} u_{n n}+\frac{2 u_{c c} u_{n}}{n_{i}}-\frac{u_{c}^{2}}{n_{i}^{2}}\right)>0$ and $\left(u_{n n}+\frac{u_{n}}{n_{i}}\right)<0$. The terms $\left(h_{i} u_{q_{h} q_{h}}+u_{q_{h}}\right) \lesseqgtr 0$ and $\left(g_{i} u_{q_{g} q_{g}}+u_{q_{g}}\right) \lesseqgtr 0$ have an indefinite sign.

As abbreviations for the substitution and income effects we use the following denotation:

$$
\begin{aligned}
& s_{n c} \equiv \lambda \frac{D_{21}}{D_{i}}, s_{n n} \equiv \lambda \frac{D_{22}}{D_{i}}, s_{n q_{h}} \equiv \lambda \frac{D_{23}}{D_{i}}, s_{n q_{g}} \equiv \lambda \frac{D_{24}}{D_{i}}, s_{n q_{z}} \equiv \lambda \frac{D_{25}}{D_{i}} \\
& s_{q_{h} c} \equiv \lambda \frac{D_{31}}{D_{i}}, s_{q_{h} n} \equiv \lambda \frac{D_{32}}{D_{i}}, s_{q_{h} q_{h}} \equiv \lambda \frac{D_{33}}{D_{i}}, s_{q_{h} q_{g}} \equiv \lambda \frac{D_{34}}{D_{i}}, s_{q_{h} q_{z}} \equiv \lambda \frac{D_{35}}{D_{i}} \\
& s_{q_{g} c} \equiv \lambda \frac{D_{41}}{D_{i}}, s_{q_{g} n} \equiv \lambda \frac{D_{42}}{D_{i}}, s_{q_{g} q_{h}} \equiv \lambda \frac{D_{43}}{D_{i}}, s_{q_{g} q_{g}} \equiv \lambda \frac{D_{44}}{D_{i}}, s_{q_{g} q_{z}} \equiv \lambda \frac{D_{45}}{D_{i}} \\
& i_{c} \equiv \frac{D_{61}}{D_{i}}, i_{n} \equiv \frac{D_{62}}{D_{i}}, i_{q_{h}} \equiv \frac{D_{63}}{D_{i}}, i_{q_{g}} \equiv \frac{D_{64}}{D_{i}}, i_{q_{z}} \equiv \frac{D_{65}}{D_{i}} .
\end{aligned}
$$

From (A2) to (A6) the comparative static results in (9) - (17) follow. The effects for parental and child-specific consumption are the following

$$
\begin{aligned}
& \frac{\partial c_{i}}{\partial \alpha}=s_{n c}+n_{i} i_{c}=-\frac{1}{D_{i}} u_{q_{h} q_{h}} u_{q_{g} q_{g}} u_{q_{z} q_{z}}\left(n_{i} u_{n n}+u_{n}\right)>0 \\
& q_{z} \frac{\partial z_{i}}{\partial \alpha}=s_{n q_{z}}+n_{i} i_{q_{z}}=-\frac{1}{D_{i}} u_{q_{h} q_{h}} u_{q_{g} q_{g}} P_{q_{z}, i}\left(n_{i} u_{c c} u_{n n}+2 u_{n} u_{c c}-\frac{u_{c}^{2}}{n_{i}}\right)>0 \\
& \frac{\partial c_{i}}{\partial \beta}=\pi\left(g_{i} s_{n c}+n_{i} s_{q_{g} c}+g_{i} n_{i} i_{c}\right)=-\frac{\pi}{D_{i}} u_{q_{h} q_{h}} u_{q_{z} q_{z}}\left(g_{i} u_{q_{g} q_{g}}+u_{q_{g}}\right)\left(n_{i} u_{n n}+u_{n}\right) \gtreqless 0
\end{aligned}
$$




$$
\begin{gathered}
q_{z} \frac{\partial z_{i}}{\partial \beta}=\pi\left(g_{i} s_{n q_{z}}+n_{i} s_{q_{g} q_{z}}+g_{i} n_{i} i_{q_{z}}\right) \\
=-\frac{\pi}{D_{i}} u_{q_{h} q_{h}} P_{q_{z}, i}\left(g_{i} u_{q_{g} q_{g}}+u_{q_{g}}\right)\left(n_{i} u_{c c} u_{n n}+2 u_{n} u_{c c}-\frac{u_{c}^{2}}{n_{i}}\right) \gtreqless 0 \\
\frac{\partial c_{i}}{\partial \gamma}=\widehat{w}_{i}\left(h_{i} s_{n c}-n_{i} s_{q_{h} c}+h_{i} n_{i} i_{c}\right)=-\frac{\widehat{w}_{i}}{D_{i}} u_{q_{g} q_{g}} u_{q_{z} q_{z}}\left(h_{i} u_{q_{h} q_{h}}+u_{q_{h}}\right)\left(n_{i} u_{n n}+u_{n}\right) \gtreqless 0 \\
q_{z} \frac{\partial z_{i}}{\partial \gamma}=\widehat{w}_{i}\left(h_{i} s_{n q_{z}}-n_{i} s_{q_{h} q_{z}}+h_{i} n_{i} i_{q_{z}}\right) \\
=-\frac{\widehat{w}_{i}}{D_{i}} u_{q_{g} q_{g}} P_{q_{z}, i}\left(h_{i} u_{q_{h} q_{h}}+u_{q_{h}}\right)\left(n_{i} u_{c c} u_{n n}+2 u_{n} u_{c c}-\frac{u_{c}^{2}}{n_{i}}\right) \gtreqless 0
\end{gathered}
$$

\section{B: Differential effects on consumption}

Using the absolute comparative static effects (9) to (17) we can derive the differential effects on consumption generated by the following policy changes.

For $d \gamma=0$ the budget-neutral increase of $\beta$ by $d \alpha=-\pi \bar{g} d \beta$ yields

$$
\begin{aligned}
\left.d c_{i}\right|_{d \alpha=-\pi \bar{g} d \beta}= & \frac{\partial c}{\partial \beta} d \beta+\frac{\partial c}{\partial \alpha} d \alpha=\pi\left[\left(s_{n c}+n_{i} i_{c}\right)\left(g_{i}-\bar{g}\right)+n_{i} s_{q_{g} c}\right] \\
& =-\frac{\pi}{D_{i}}\left(n_{i} u_{n n}+u_{n}\right) u_{q_{h} q_{h}} u_{q_{z} q_{z}}\left[\left(g_{i}-\bar{g}\right) u_{q_{g} q_{g}}+u_{q_{g}}\right] \\
\left.d z_{i}\right|_{d \alpha=-\pi \bar{g} d \beta}= & \frac{\partial q_{z}}{\partial \beta} d \beta+\frac{\partial q_{z}}{\partial \alpha} d \alpha=\pi\left[\left(s_{n q_{z}}+n_{i} i_{q_{z}}\right)\left(g_{i}-\bar{g}\right)+n_{i} s_{q_{g} q_{z}}\right] \\
& =-\frac{\pi}{D_{i}}\left(n_{i} u_{c c} u_{n n}+2 u_{n} u_{c c}-\frac{u_{c}^{2}}{n_{i}}\right) u_{q_{h} q_{h}} P_{q_{z}, i}\left[\left(g_{i}-\bar{g}\right) u_{q_{g} q_{g}}+u_{q_{g}}\right]
\end{aligned}
$$

For $d \beta=0$ a budget-neutral increase of $\gamma$ by $d \alpha=-\widehat{\widehat{w}} \bar{h} d \gamma$ yields

$$
\begin{aligned}
\left.d c_{i}\right|_{d \alpha=-\bar{w} \bar{h} d \gamma}= & \frac{\partial c}{\partial \gamma} d \gamma+\frac{\partial c}{\partial \alpha} d \alpha=-\left(\overline{\widehat{w}} \bar{h}-\widehat{w}_{i} h_{i}\right)\left(s_{n c}+n_{i} i_{c}\right)-\widehat{w}_{i} n_{i} s_{q_{h} c} \\
& =\frac{1}{D_{i}} u_{q_{g} q_{g}} u_{q_{z} q_{z}}\left(n_{i} u_{n n}+u_{n}\right)\left[\left(\overline{\widehat{w}} \bar{h}-\widehat{w}_{i} h_{i}\right) u_{q_{h} q_{h}}-\widehat{w}_{i} u_{q_{h}}\right] \\
\left.d z_{i}\right|_{d \alpha=-\bar{w} h d \gamma}= & \frac{\partial q_{z}}{\partial \gamma} d \gamma+\frac{\partial q_{z}}{\partial \alpha} d \alpha=-\left(\overline{\widehat{w}} \bar{h}-\widehat{w}_{i} h_{i}\right)\left(s_{n q_{z}}+n_{i} i_{q_{z}}\right)-\widehat{w}_{i} n_{i} s_{q_{h} q_{z}} \\
& =\frac{1}{D_{i}} u_{q_{g} q_{g}} P_{q_{z}, i}\left(n_{i} u_{c c} u_{n n}+2 u_{n} u_{c c}-\frac{u_{c}^{2}}{n_{i}}\right)\left[\left(\overline{\widehat{w}} \bar{h}-\widehat{w}_{i} h_{i}\right) u_{q_{h} q_{h}}-\widehat{w}_{i} u_{q_{h}}\right]
\end{aligned}
$$


For $d \alpha=0$ the budget-neutral increase of $\beta$ by $d \gamma=-\frac{\pi \bar{g}}{\overline{\widehat{w}} \bar{h}} d \beta$ yields

$$
\begin{aligned}
\left.d c_{i}\right|_{d \gamma=-\frac{\pi \bar{g}}{\bar{w} \bar{h}} d \beta}= & \frac{\partial c}{\partial \beta} d \beta+\frac{\partial c}{\partial \gamma} d \gamma=\pi\left(g_{i}-\frac{\widehat{w}_{i}}{\widehat{\widehat{w}}} \frac{h_{i}}{\bar{h}} \bar{g}\right)\left(s_{n c}+n_{i} i_{c}\right)+\pi n_{i}\left(s_{q_{g} c}+\frac{\bar{g}}{\bar{h}} \frac{\widehat{w}_{i}}{\widehat{\widehat{w}}} s_{q_{h} c}\right) \\
& =-\frac{\pi}{D_{i}}\left(n_{i} u_{n n}+u_{n}\right) u_{q_{z} q_{z}}\left[\left(g_{i}-\frac{\widehat{w}_{i}}{\overline{\widehat{w}}} \frac{h_{i}}{\bar{h}} \bar{g}\right) u_{q_{h} q_{h}} u_{q_{g} q_{g}}\right. \\
& \left.+u_{c}\left(u_{q_{h} q_{h}} P_{q_{g}, i}-\frac{\bar{g}}{\bar{h}} \frac{\widehat{w}_{i}}{\widehat{\widehat{w}}} u_{q_{g} q_{g}} P_{q_{h}, i}\right)\right] \\
\left.d z_{i}\right|_{d \gamma=-\frac{\pi \bar{g}}{\bar{w} \bar{h}} d \beta}= & \frac{\partial q_{z}}{\partial \beta} d \beta+\frac{\partial q_{z}}{\partial \gamma} d \gamma \\
& =\pi\left(g_{i}-\frac{\widehat{w}_{i}}{\overline{\widehat{w}}} \frac{h_{i}}{\bar{h}} \bar{g}\right)\left(s_{n q_{z}}+n_{i} i_{q_{z}}\right)+\pi n_{i}\left(s_{q_{g} q_{z}}+\frac{\bar{g}}{\bar{h}} \frac{\widehat{w}_{i}}{\widehat{\widehat{w}}} s_{q_{h} q_{z}}\right) \\
& =-\frac{\pi}{D_{i}}\left(n_{i} u_{c c} u_{n n}+2 u_{n} u_{c c}-\frac{u_{c}^{2}}{n_{i}}\right) P_{q_{z}, i}\left[\left(g_{i}-\frac{\widehat{w}_{i}}{\overline{\widehat{w}}} \frac{h_{i}}{\bar{h}} \bar{g}\right) u_{q_{h} q_{h}} u_{q_{g} q_{g}}\right. \\
& \left.+u_{c}\left(u_{q_{h} q_{h}} P_{q_{g}, i}-\frac{\bar{g}}{\bar{h}} \frac{\widehat{w}_{i}}{\widehat{\widehat{w}}} u_{q_{g} q_{g}} P_{q_{h}, i}\right)\right]
\end{aligned}
$$

